Check for updates

Cite this: RSC Adv., 2019, 9, 3185

Received 30th September 2018 Accepted 24th December 2018

DOI: $10.1039 / \mathrm{c} 8 \mathrm{ra0} 8112 \mathrm{c}$

rsc.li/rsc-advances

\section{Recent advances in the application of nano- catalysts for Hiyama cross-coupling reactions}

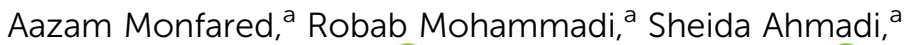 \\ Mohammad Nikpassand (D) *b and Akram Hosseinian (D ${ }^{c}$
}

This mini-review highlights the recent developments in the field of metal nanoparticle (NP) catalyzed Hiyama cross-coupling reactions. Most of the nanocatalysts outlined here allow convenient and green synthetic pathways for the construction of carbon-carbon bonds in water and fluoride-free conditions. Literature has been surveyed from 2005 to February 2018.

\section{Introduction}

Transition-metal-catalyzed cross-coupling reactions have become a routine, straightforward, and powerful method for the preparation of carbon-carbon ${ }^{1}$ and carbon-heteroatom ${ }^{2}$ bonds in synthetic organic chemistry. Among the various carbon-carbon cross-coupling reactions, Heck, Stille, Negishi, Sonogashira, Suzuki, Hiyama, and Kumada-Corriu reactions find maximum application in industrial processes. ${ }^{3}$ In comparison with Suzuki coupling with its problems in preparing and purifying arylboronic acids and the Negishi, Stille, and Kumada-Corriu coupling

${ }^{a}$ Department of Chemistry, Payame Noor University, P. O. Box, 19395-3697, Tehran, Iran

${ }^{b}$ Department of Chemistry, Rasht Branch, Islamic Azad University, Rasht, Iran. E-mail: nikpassand@iaurasht.ac.ir

${ }^{c}$ School of Engineering Science, College of Engineering, University of Tehran, P. O. Box 11365-4563, Tehran, Iran

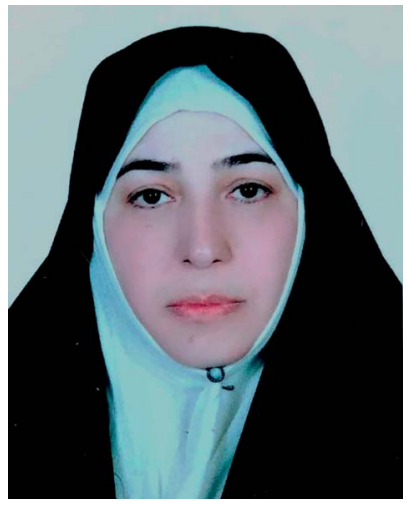

Aazam Monfared was born in Tehran, Iran, in 1965. She received her B.S. degree in Pure Chemistry from University of Shahid Beheshti, Tehran, Iran, and her M.S. degree in Organic chemistry from Shahid Beheshti University, Tehran, Iran, in 1991 under the supervision of Prof. A. Rustaiyan. She received her PhD degree in 1999 under the supervision of Prof. A. Rustaiyan in Shahid Beheshti University, Tehran, Iran. Now, she is working at Payame Noor University of Tehran as Associate Professor. Her research interests include organic synthesis, phytochemistry, drug synthesis, nano chemistry, methodologies and theoretical chemistry. reactions that use unstable organozinc, toxic organotin, and violent organomagnesium reagents, respectively, the Hiyama coupling uses inexpensive, low-toxicity, broadly available, and chemically stable organosilane reagents making these coupling reactions more attractive from an environmental point of view., However, the less polarized carbon-silicon bonds of organosilicon reagents make these reagents less reactive toward electrophiles than other organometallic nucleophiles. ${ }^{4}$ This weak bond requires fluoride ions for its activation and this can be considered as the main disadvantage for this coupling reaction. ${ }^{6}$

Transition-metal nanoparticles (NPs) have attracted extraordinary attention in recent years for potential applications in catalysts due to their high surface to volume ratio and reactive morphologies. ${ }^{7-9}$ Without the slightest doubt, their use in cross-coupling reactions constitutes one of their most important applications. $^{\mathbf{1 0 - 1 2}}$ In the last decade, the use of metal nanoparticles as highly effective catalysts in Hiyama cross-coupling reactions has attracted more and more attention. Interestingly, in the presence

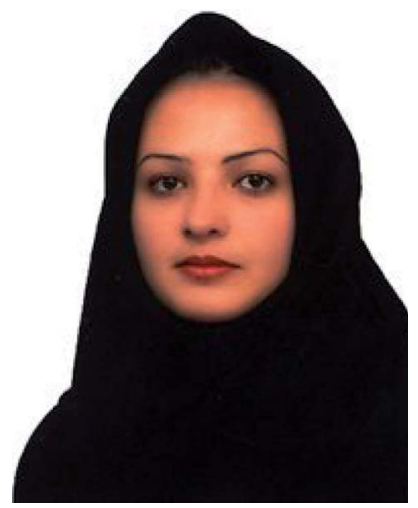

Robab Mohammadi was born in Tabriz, Iran, in 1979. She received her B.S. degree in Pure Chemistry from University of Tabriz, Iran, and her M.S. degree in applied chemistry from Islamic Azad University, Tabriz Branch, Tabriz, Iran, in 2008 under the supervision of $\mathrm{Dr} L$. Edjlali. She received her $P h D$ degree in 2012 under the supervision of Prof. M. Rabani and Prof. B. Massoumi from Islamic Azad University, Tehran Shomal Branch, Tehran, Iran. Now she is working at Payame Noor University of Tabriz as Associate Professor. Her research interests include nano materials synthesis and new methodologies in material synthesis. 
of these catalysts, numerous fluoride-free Hiyama coupling reactions have been reported and the interest in this environmentally friendly reaction has increased. In continuation of our recent works, ${ }^{\mathbf{8 1 3 , 1 4}}$ in this review, we will highlight the advances in metal nanoparticle catalyzed Hiyama coupling reactions from 2005 to February 2018, hoping that it will stimulate researchers to develop truly efficient catalytic systems for this interesting and important coupling reaction. ${ }^{\mathbf{1 4}}$ It is noted that we have classified these reactions based on the starting materials (e.g. coupling of aryl siloxanes with aryl halides and coupling of vinyl silanes with aryl halides) and the type of catalysts (monometallic nanoparticles and bimetallic nanoparticles).

\section{Coupling of aryl siloxanes with aryl halides}

The biaryl moiety is the core structure of several drugs such as losartan (anti-hypertensive), telmisartan (anti-

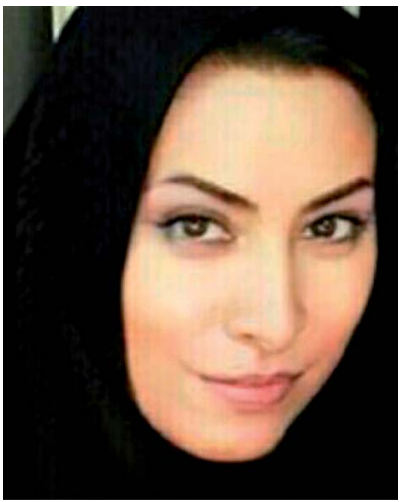

Sheida Ahmadi was born in Miyaneh, Iran. She has received her B.S. degree in Applied Chemistry from Islamic azad University, Tehran, Iran, in 1997, and her M.S. degree in inorganic chemistry from Shahid Bahonar University, kerman, Iran, in 2007 under the supervision of Prof. $S$. J. Fatemi. She received her PhD degree in 2017 under the supervision of Prof. M. Hakimi in Payam Noor university, Tehran, Iran. Now she is working at Payame Noor University of Tehran as assistant professor. Her research interests include inorganic polymer, synthesis of the inorganic complexes and bioinorganic chemistry.

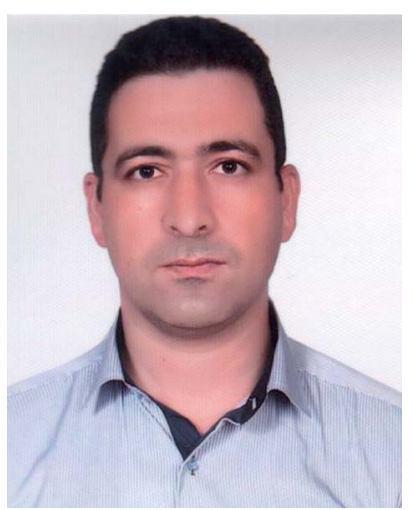

Mohammad Nikpassand was born in Soumehsara, Iran, in 1980. He received his B.Sc. degree in Pure Chemistry from Zanjan University, Zanjan, Iran, and his M.Sc. degree in Organic chemistry from Guilan University, Rasht, Iran, in 2005 under the supervision of Prof. $M$. Mamaghani. He received his PhD degree in 2009 under the supervision of Prof. M. Mamaghani in Guilan University, Rasht, Iran. Now he is working at Rasht branch of Islamic Azad University as Associate Professor. His research interests include organic synthesis, green chemistry, azo dyes synthesis, new nanochemistry and methodologies and calculated chemistry. hypertensive), knipholone (anti-plasmodial), felbinac (antiinflammatory), imatinib (anti-cancer), and febuxostat (gout and hyperuricemia treatment). It is also present in several pesticides. $^{15}$ Numerous synthetic methods have been designed for the preparation of functionalized biaryls with the majority of them relying on the carbon-carbon crosscoupling reactions. ${ }^{\mathbf{1 5 , 1 6}}$ One of the most common processes involves the metal-catalyzed Hiyama coupling reactions of aryl siloxanes with aryl halides. Over the past decade, several mono- and bi-metallic nanoparticles have been developed as effective catalysts for these environmentally friendly reactions. In this section, we highlight the advances in this novel and interesting research arena. The section is divided into two major subsections. The first will discuss monometallic nanoparticles catalyzed coupling reactions, while the second focuses exclusively on bimetallic nanoparticles catalyzed reactions.

\subsection{Monometallic nanocatalysts}

2.1.1. Palladium. The first synthesis of biaryls through palladium nanoparticles catalyzed Hiyama coupling reactions was reported by Sarkar and co-workers in $2007,{ }^{17}$ who treated various aryl siloxanes 1 with aryl bromides 2 in the presence of $1 \mathrm{~mol} \%$ of colloidal Pd NPs (generated in situ from $\mathrm{K}_{2} \mathrm{PdCl}_{4}$ and a Fischer carbene complex of tungsten as the reductant with PEG-6000 as the capping agent) as the catalyst and 5 equiv. of $\mathrm{NaOH}$ as a base in the most benign solvent, water. The reactions were performed under air condition at $90{ }^{\circ} \mathrm{C}$ and provided the corresponding biaryls 3 in high to almost quantitative yields (Scheme 1). Several sensitive functionalities (Cl, OMe, $\mathrm{NO}_{2}$, $\mathrm{CHO}, \mathrm{Ac})$ were well-tolerated under the optimized conditions. Therefore, the obtained coupling products can easily undergo further derivatization by typical organic reactions. It should be mentioned that with increasing amount of the stabilizer PEG, both the size of nanoparticles and the yield of product decreases (Fig. 1). The authors explained this fact by inverse correlation between the catalytic activity and stability. The best results was

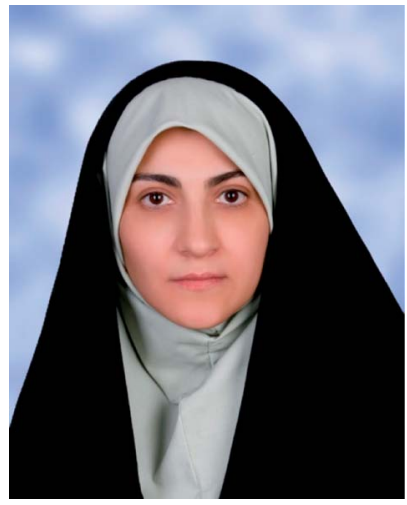

Akram Hosseinian was born in Ahar, Iran, in 1973. She received her B.S. degree in Pure Chemistry from University of Tehran, Iran, and her M.S. degree in inorganic chemistry from Tarbiat Modares University, Tehran, Iran, in 2000 under the supervision of Prof. A. R. Mahjoub. She completed her PhD degree in 2007 under the supervision of Prof. A. R. Mahjoub. Now she is working at University of Tehran as Associate Professor. Her research interests include inorganic and organic synthesis, new methodologies in nano material synthesis. 


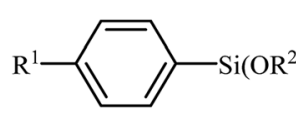

1

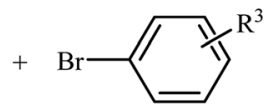

2

$\mathrm{R}^{1}=\mathrm{H}, \mathrm{Me}$

$\mathrm{R}^{2}=\mathrm{Me}, \mathrm{Et}$

$\mathrm{R}^{3}=\mathrm{H}$, 4-Me, 4-OMe, 4-Cl, 4- $\mathrm{NO}_{2}$, 4-CHO, 4-COMe, 3-Me, 3-OMe, 3- $\mathrm{NO}_{2}$, 3-CHO, 2-Me, 2-CHO

Scheme 1 Hiyama coupling of aryl siloxanes 1 with aryl bromides 2 catalyzed by a Pd NP in water developed by Sarkar.

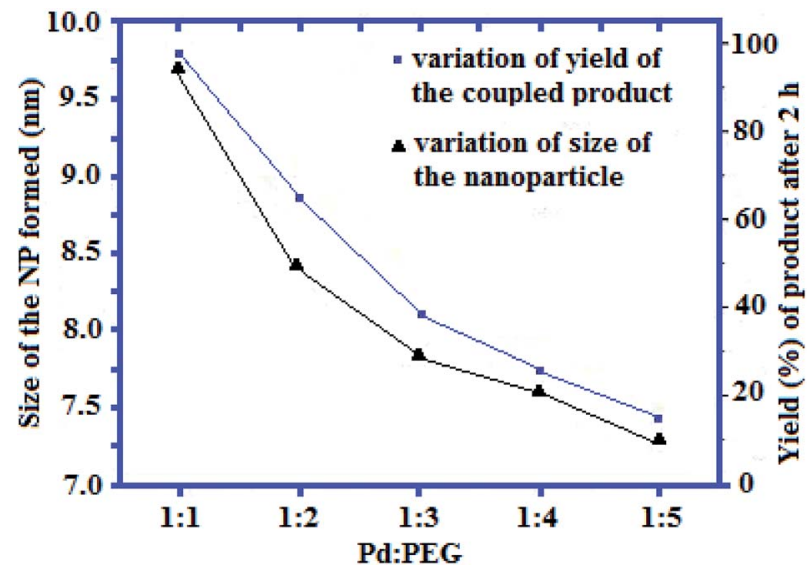

Fig. 1 Plot of the size of NP as a function of Pd/PEG molar ratio and yield (\%) of the coupled product.

obtained by using Pd/PEG with $1: 1$ ratio (particle size of 9.70 $\mathrm{nm})$.

Subsequently, in a closely related investigation, the group of Ranu also described that the cross-coupling of various aryl siloxanes with aryl iodides/bromides in the presence of in situ generated palladium nanoparticles (3-6 nm) from $\mathrm{Na}_{2} \mathrm{PdCl}_{4} /$ sodium dodecyl sulfate produced the corresponding substituted biaryls in good to excellent yields. Noteworthy, the catalyst was reusable and could be recovered and reused for three reaction runs with only a gradual loss of efficiency. Mechanistically, the reaction is believed to proceed through the

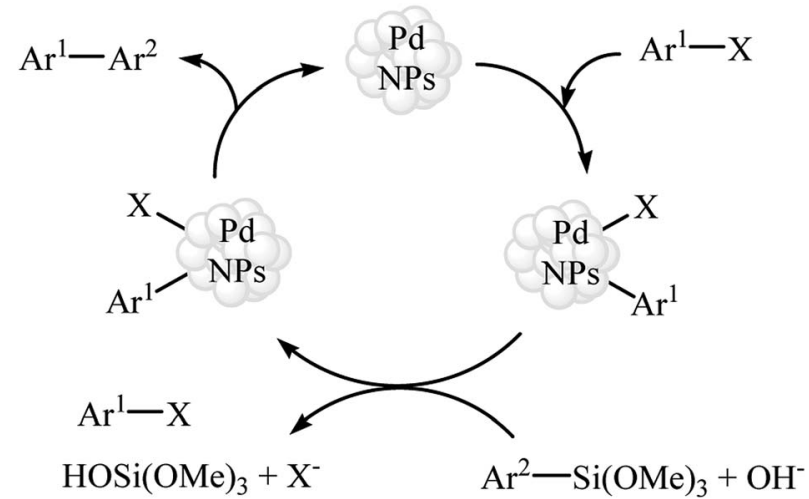

Scheme 2 Plausible mechanism for the Pd NPs-catalyzed coupling of aryl siloxanes 1 with aryl bromides 2 in water. standard oxidative addition/transmetallation/reductive elimination sequential process (Scheme 2). ${ }^{18}$

In 2010, Komáromi, Szabó, and Novák compared the catalytic activity of several commercially available Pd/charcoal catalysts in Hiyama cross-coupling reaction of trimethoxyphenylsilane 4 with 3-bromotoluene 5 employing $\mathrm{PPh}_{3}$ as a ligand and tetrabutylammonium fluoride (TBAF) as an activating additive in DMF (Fig. 2). Investigations showed that some catalysts had completely different activity in this reaction. The $\mathrm{Pd} / \mathrm{C}$ catalyst supplied by Merck and the palladium catalyst deposited onto the multi-walled carbon nanotubes (MWCNT) gave almost full conversions, but Norit A and Evonik 196 KP/D did not show significant catalytic activity. This results showed the importance of the choice of carbon carrier. It is noted that the choice of DMF and TBAF was also crucial for the reaction; other solvents and fluoride sources proved to be unsuitable for this coupling. ${ }^{19}$ Inspired by this work, Kim and co-workers designed a novel multiwall carbon nanotube supported palladium nanoparticles (Pd-NP/MWCNT) based on the anchoring of Pd-NPs onto the surface of thiolated carbon nanotube, as shown in Fig. 3. The authors explained that Pd-NPs are anchored to the surface of the CNTs due to their interaction with the free electron pairs of the $\mathrm{S}$ atoms. The catalytic activity of the system was investigated for Hiyama coupling reaction of trimethoxyphenylsilane and 4-iodotoluene in the presence of TBAF as an activator in $p$-xylene at $50{ }^{\circ} \mathrm{C}$. The expected 4-methylbiphenyl was obtained in $98 \%$ yield. ${ }^{20}$

In an innovative design, Shah and Kaur impregnated Amberlite XAD-4, a non-functional macroporous commercial resin, with palladium nanoparticles to obtain a Pd-NPs@XAD-4 catalyst. The method used for nanoparticles impregnation was simple and involved sorption of $\mathrm{Pd}(\mathrm{OAc})_{2}$ in the resin followed by reduction using aqueous $\mathrm{NaBH}_{4}$ solution. Transmission electron microscopy (TEM) images demonstrated that these conditions furnished palladium nanoparticles with size ranging from 5 to $10 \mathrm{~nm}$. The catalytic utility of the catalyst was investigated for Hiyama cross-coupling reactions. Thus, a variety of functionalized biaryls 8 were synthesized via the Pd-NPs@XAD4 catalyzed coupling of trimethoxyphenylsilane 4 with aryl bromides/chlorides 7 under microwave irradiation and basic conditions (Scheme 3). The protocol is also applicable for the coupling of heteroaryl halides with aryl siloxanes. Broad substrate scope, high turnover number (TON), turnover frequency (TOF) and yields were the merits of this synthetic protocol. Notably, the catalyst could be recovered and reused for 

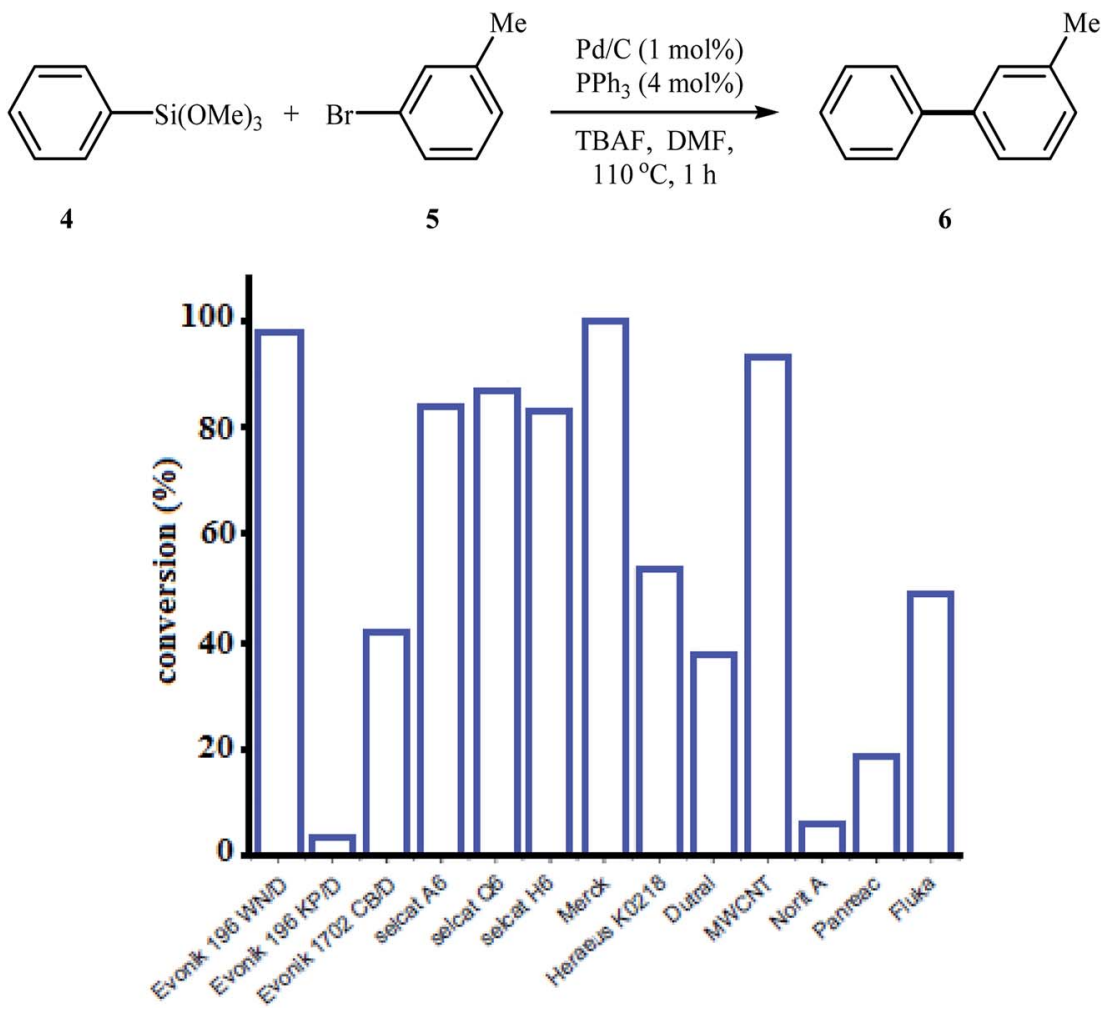

Fig. 2 Comparison of the catalytic activity of several commercially available Pd/charcoal catalysts in Hiyama cross-coupling reaction of trimethoxyphenylsilane 4 with 3-bromotoluene 5 .
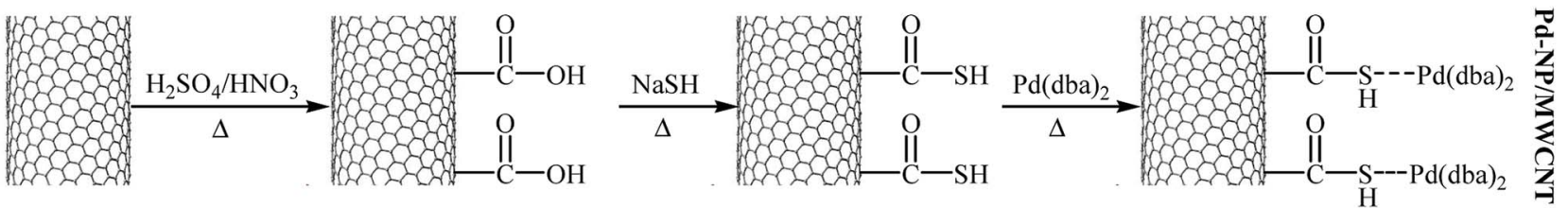

Fig. 3 Schematic illustrations of the synthesis for Pd-NP/MWCNT.

five reaction runs with no remarkable loss of activity. ${ }^{21}$ In a related study, Becht and Drian along with their co-workers prepared a phosphine-derived polystyrene-supported palladium catalyst and successfully applied it for the Hiyama crosscoupling reactions of aryl siloxanes with aryl iodides in toluene at $100{ }^{\circ} \mathrm{C}$. A broad spectrum of substituted aryl iodides were reacted with different aryl siloxanes in the presence of only $0.1 \mathrm{~mol} \%$ of supported palladium, furnishing the corresponding biaryls in good to excellent yields. ${ }^{22}$
In 2013, Premi and Jain developed an efficient Pd NPscontaining ionic liquid $10\left\{\mathrm{Pd}[\mathrm{CN}-\mathrm{bmim}] \mathrm{PF}_{6}\right\}$ by simple heating $\left(140{ }^{\circ} \mathrm{C}\right)$ of $\mathrm{Pd}(\mathrm{OAc})_{2}$ with nitrile-functionalized 3-(3-cyanopropyl)-1-methyl-1 $H$-imidazol-3-ium hexafluorophosphate $\mathbf{9}$ $\left\{[\mathrm{CN}-\mathrm{bmim}] \mathrm{PF}_{6}\right\}$ in acetonitrile (Fig. 4). The size of the $\mathrm{Pd}$ nanoparticles was determined by DLS, TEM, and SEM and revealed the catalyst presented an average particle size range of 2-5 nm. This ionic liquid was tested as an in situ catalyst in the Hiyama cross-coupling of trimethoxyphenylsilane 4 with

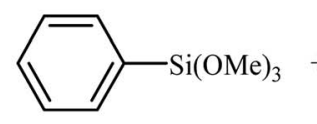

$4,(1.5 \mathrm{mmol})$

$\mathrm{X}=\mathrm{Cl}, \mathrm{Br}$

$\mathrm{R}=\mathrm{H}, 4-\mathrm{OMe}, 4-\mathrm{NO}_{2}$, 4-COMe, 4-CHO, 4-NHCOMe, 3-Me, 2-COMe, 2-CHO

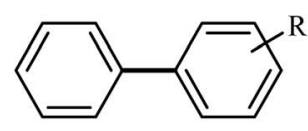

8

10 examples $(76-96 \%)$

(average yield: $90.5 \%$ )

Scheme 3 Pd-NPs@XAD-4 catalyzed coupling of trimethoxyphenylsilane 4 with aryl bromides/chlorides 7 reported by Shah and Kaur. 


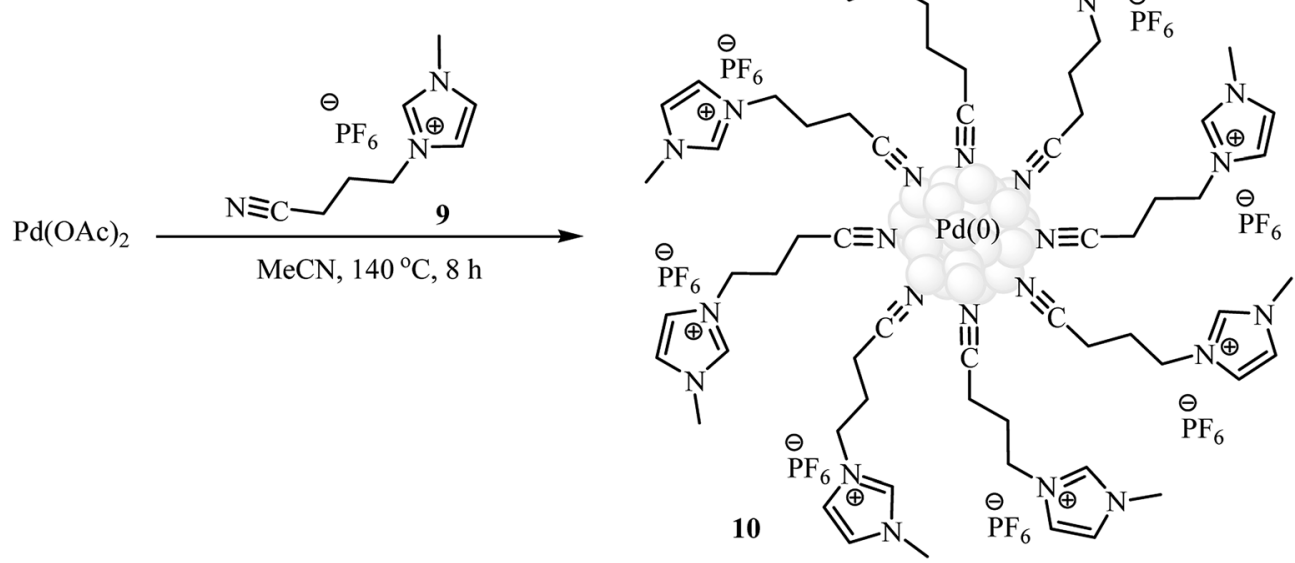

Fig. 4 Synthesis of $\mathrm{Pd}\left[\mathrm{CN}\right.$-bmim] $\mathrm{PF}_{6}$ (10) by heating of $\mathrm{Pd}(\mathrm{OAc})_{2}$ with $\left[\mathrm{CN}\right.$-bmim] $\mathrm{PF}_{6}(9)$ in $\mathrm{MeCN}$.

(hetero)aryl halides $\mathbf{1 2}$ in the presence of 1-butyl-3methylimidazolium fluoride $\mathbf{1 1}\{[\mathrm{bmim}] \mathrm{F}\}$ as an activator, providing good yields and selectivities of coupling products $\mathbf{1 3}$ (Scheme 4a). The catalyst was reused four times maintaining the high yields. The proposed mechanism for this reaction involves the initial formation of aryl-Pd complex A through the oxidative addition of (hetero)aryl halide 12 to the $\operatorname{Pd}[\mathrm{CN}-\mathrm{bmim}]$ $\mathrm{PF}_{6}$ catalyst. This intermediate $\mathbf{A}$ upon anion exchange with [bmim]F leads to the intermediate $\mathbf{B}$ which undergoes transmetalation with trimethoxyphenylsilane 4 to afford intermediate complex C. Finally, reductive elimination of this complex produces the observed biaryls 13 (Scheme 4b). ${ }^{23}$
In 2014, the trimethylsilylated mesoporous SBA-15 (TMSSBA-15) was used for immobilizing $\operatorname{Pd}(0)$ nanoparticles, by Huang et $a .^{24}$ The catalytic activity of the obtained catalyst, Pd@TMS-SBA-15 was investigated for the synthesis of biaryls 16 via the Hiyama cross-coupling reaction of triethoxyphenylsilanes 14 with aryl bromides/chlorides 15 in the presence of tetra- $n$-butylammonium fluoride trihydrate $\left(\mathrm{TBAF} \cdot 3 \mathrm{H}_{2} \mathrm{O}\right)$ as a fluoride source and $\mathrm{AcOH}$ as a proton source at $100{ }^{\circ} \mathrm{C}$. The results established that the low amount of the prepared catalyst $(0.5 \mathrm{~mol} \%)$ could furnish the expected coupling products in moderate to high yields (Scheme 5). However, 4-chloroanisole failed to participate in this reaction

(a)

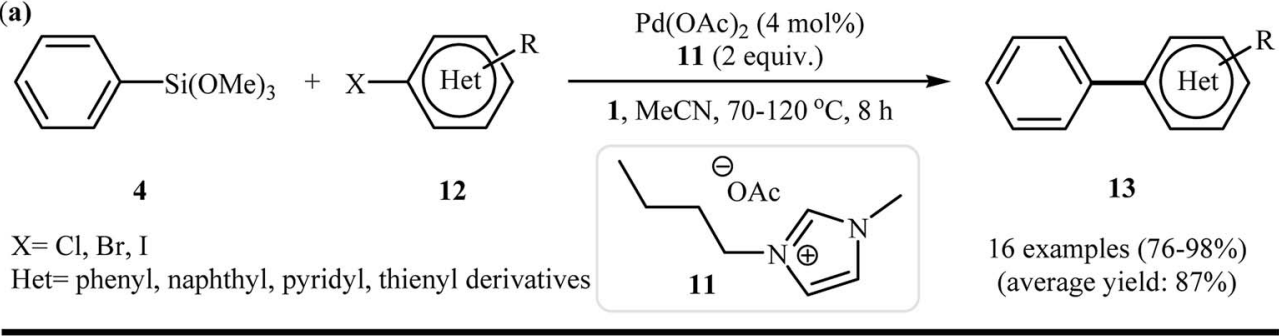

(b)

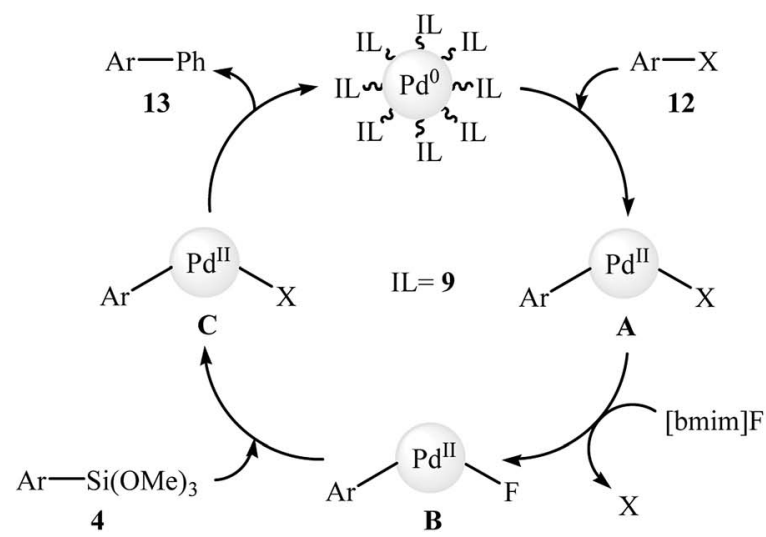

Scheme 4 (a) Jain's synthesis of biaryls 13; (b) mechanistic proposal for the formation of biaryls 13. 


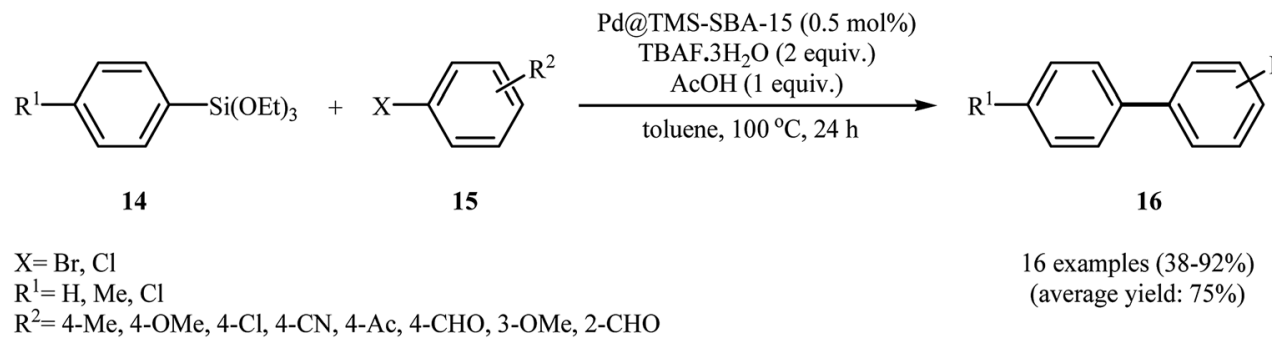

Scheme 5 PdaTMS-SBA-15 catalyzed Hiyama coupling of triethoxyphenylsilanes 14 with aryl halides 15

Table 1 Comparing the catalytic activity of Pd@M-SBA-15, Pd@P-SBA-15, Pd@PS-S15, and Pd/C

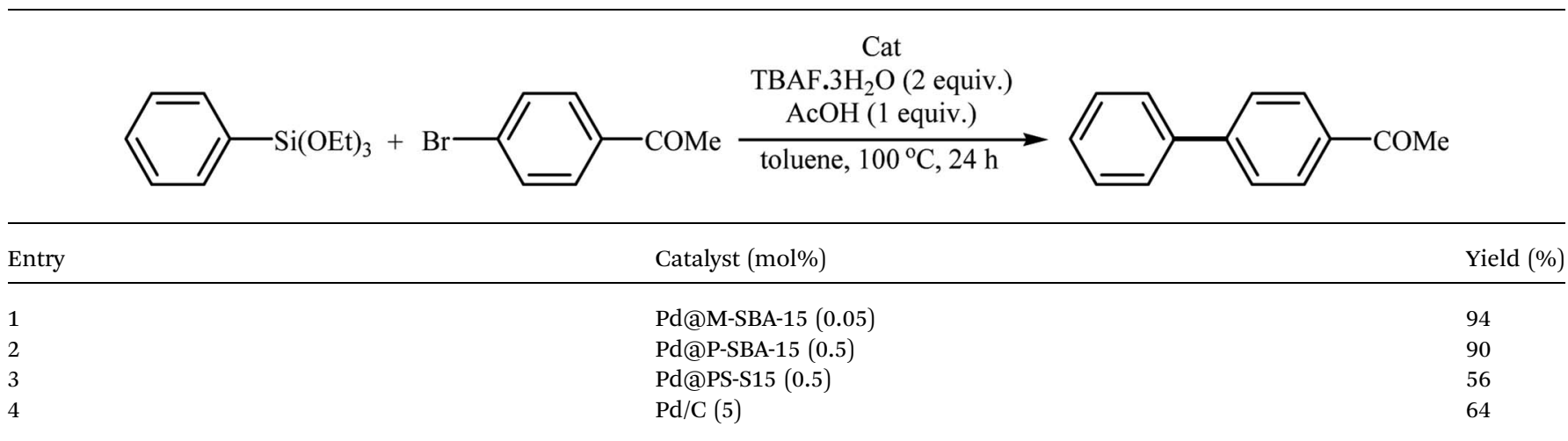
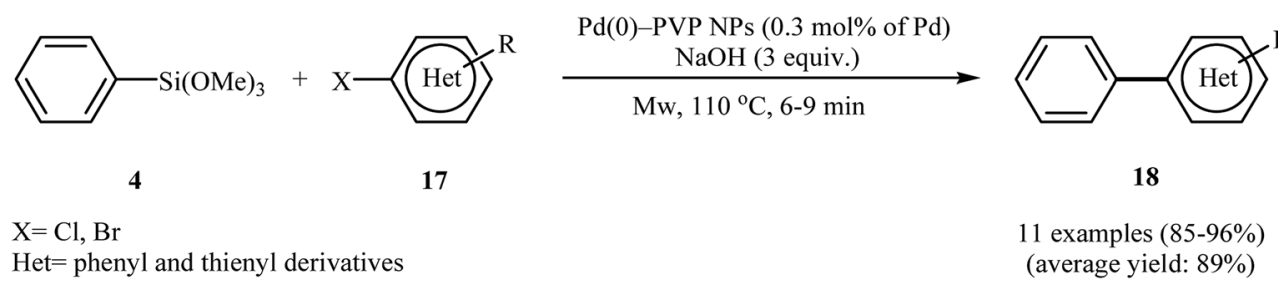

Scheme 6 Pd(0)-PVP NPs catalyzed synthesis of biaryls 13 reported by Kaur.

and sterically hindered 2-bromoanisole gave the corresponding product in only $13 \%$ yield. Notably, an attempt of catalyst reuse showed noticeable loss of catalytic activity from $92 \%$ in the first run to approximately $22 \%$ in the fourth run. The authors compared the catalytic activity of the catalyst with Pd@P-SBA15, Pd@PS-S15, and Pd/C. The results demonstrated superior catalytic activity of the synthesized catalyst (Table 1). In the same year, Shah and Kaur found that ligand-free cross-coupling of trimethoxyphenylsilane $\mathbf{4}$ with aryl halides 17 could be successfully carried out using polyvinylpyrrolidone (PVP) stabilized colloidal palladium nanoparticles $(2-5 \mathrm{~nm})[\operatorname{Pd}(0)-$ PVP NPs] as the catalytic system and sodium hydroxide as the activator under microwave irradiation (Scheme 6). Noteworthy, the catalyst could be reused for four reaction runs without significant loss of activity. ${ }^{25}$

With the objective of designing a greener procedure to biaryls through palladium catalyzed Hiyama coupling reactions, Ohtaka and his group were able to demonstrate that linear polystyrene-stabilized PdO nanoparticles (PS-PdONPs) could efficiently catalyze the coupling of aryl trimethoxysilanes 19 with aryl bromides 20 in water under fluoride-free conditions. The process was carried out in the presence of 1.0 equiv. of tetrabutylammonium chloride (TBAC) under basic conditions, and provided functionalized biaryls 21 in moderate to high yields (Scheme 7). However, sterically hindered ortho-substituted aryl halides did not work well under this conditions. The catalyst was reusable and could catalyze five reaction cycles without detrimental loss of catalytic activity. The TEM image of the recovered catalyst showed that the size of the nanoparticles $(2.1 \pm 0.3 \mathrm{~nm})$ was maintained even after the third run. Moreover, leaching of palladium species was not detected by ICP-AES analysis. The same reaction was also performed by using PS-PdNPs in place of PS-PdONPs. Surprisingly, under this reaction conditions the expected coupling product was not observed. The authors suggested that the difference in catalytic activity between PS-PdONPs and PS-PdNPs may be caused by the difference in mechanisms. ${ }^{26}$

Very recently, the same research team studied a detailed mechanism for the Hiyama coupling reaction in water using PSPdONPs as a catalyst. Stepwise reactions, hot filtration, and 


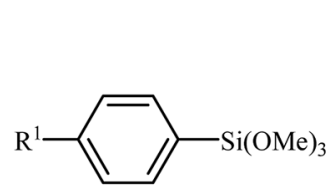

19

$\mathrm{R}^{1}=\mathrm{H}, \mathrm{Me}, \mathrm{OMe}$

$\mathrm{R}^{2}=\mathrm{H}, 4-\mathrm{Me}, 4-\mathrm{OMe}, 4-\mathrm{NO}_{2}, 2-\mathrm{Me}, 2,6-\mathrm{Me}_{2}$

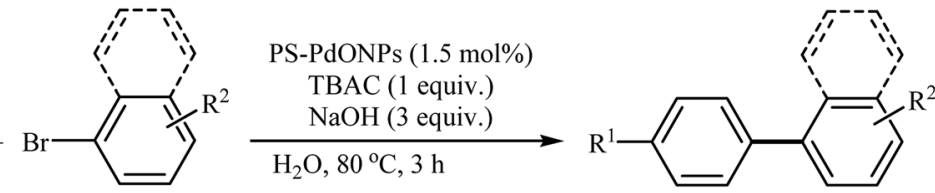

21

9 examples $(12-88 \%)$

(average yield: 66\%)

Scheme 7 Carbon-carbon cross-coupling reaction between aryl trimethoxysilanes 19 with aryl bromides 20 using Ps-PDONPs as catalyst in water.

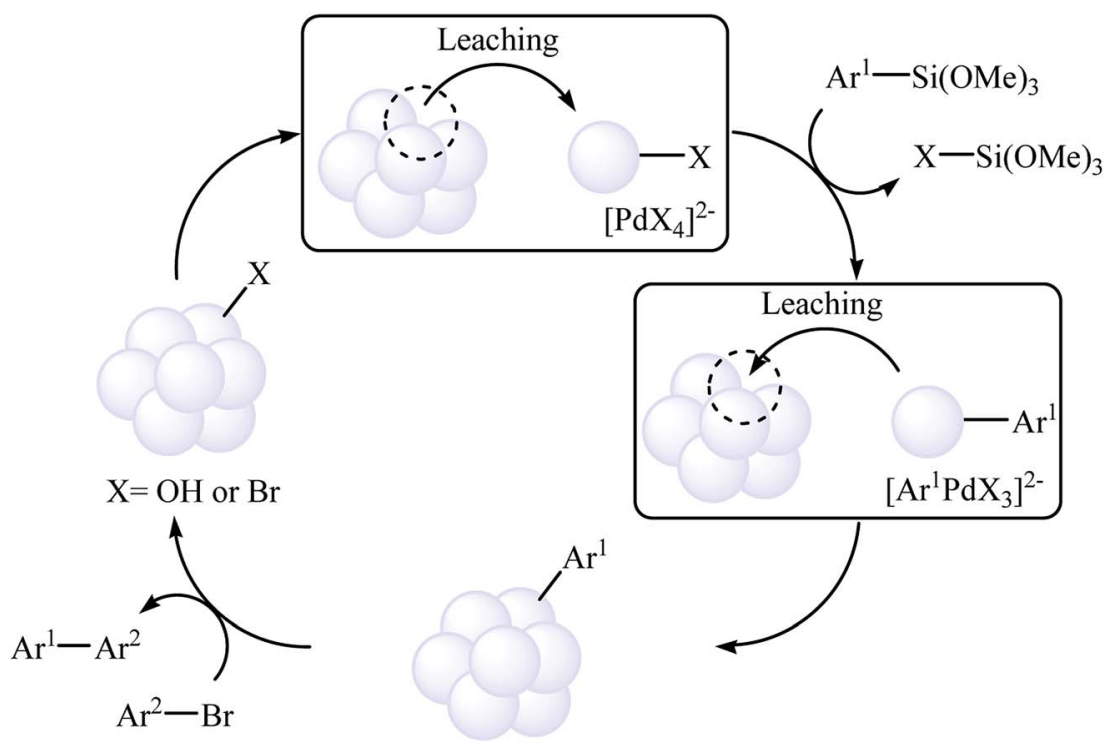

Scheme 8 Mechanistic proposal for the reaction in Scheme 7.

leaching tests showed that this reaction proceeds through a different mechanism from the commonly accepted one that starts from the oxidative addition of an aryl halide to a $\operatorname{Pd}(0)$ species. As shown in Scheme 8, the proposed Pd(II) catalytic cycle starts with a local leaching of palladium under basic condition. Next, this palladium species reacts with aryl trimethoxysilane and then immediately re-stabilizes on the catalyst surface. Finally, the generated Pd-Ar species reacts with aryl bromide to give the expected product. ${ }^{27}$

Recently, a range of magnetic nanoparticles (MNPs) have been developed and exploited as catalysts for a variety of chemical transformations. Among the various magnetic nanoparticles, $\mathrm{Fe}_{3} \mathrm{O}_{4}$ nanoparticles have drawn much attention because these chemically stable nanoparticles can be prepared by simple methods, which can be used as an efficient alternative to heterogeneous catalyst supports..$^{28}$ In 2011, Sreedhar, Kumar, and Yada reported magnetically separable $\mathrm{Fe}_{3} \mathrm{O}_{4} @$ @PdNPs consisting of $\mathrm{Fe}_{3} \mathrm{O}_{4}$ NPs of 25-50 nm in diameter and PdNPs of $5 \mathrm{~nm}$ encaged in $\mathrm{Fe}_{3} \mathrm{O}_{4}$ as highly active catalyst for fluoride-free Hiyama cross-coupling reaction (Scheme 9). The reported catalyst was highly active for differently substituted aryl siloxanes $\mathbf{2 2}$ and aryl bromides $\mathbf{2 3}$, and resulted in a high yield of corresponding biaryl 24 using $\mathrm{NaOH}$ as a base in water. After the reaction catalyst was recovered by an external magnet and

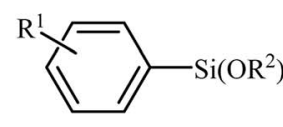

22

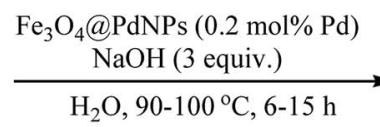

$\mathrm{H}_{2} \mathrm{O}, 90-100{ }^{\circ} \mathrm{C}, 6-15 \mathrm{~h}$

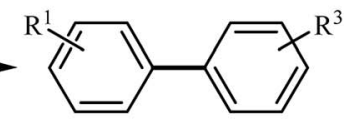

24

$\mathrm{R}^{1}=\mathrm{H}, 4-\mathrm{Me}, 4-\mathrm{OMe}, 2-\mathrm{OMe}$

$\mathrm{R}^{2}=\mathrm{Me}, \mathrm{Et}$

$\mathrm{R}^{3}=\mathrm{H}$, 4-Me, 4-OMe, 4-Ac, 4-F, 3-OMe, 2-Me, 2-OMe, 2,4,6-Me 3 , 1-naphthyl

18 examples $(65-92 \%)$

(average yield: $82 \%$ )

Scheme 9 Hiyama coupling using magnetically separable $\mathrm{Fe}_{3} \mathrm{O}_{4} @ \mathrm{PdNPs}$. 


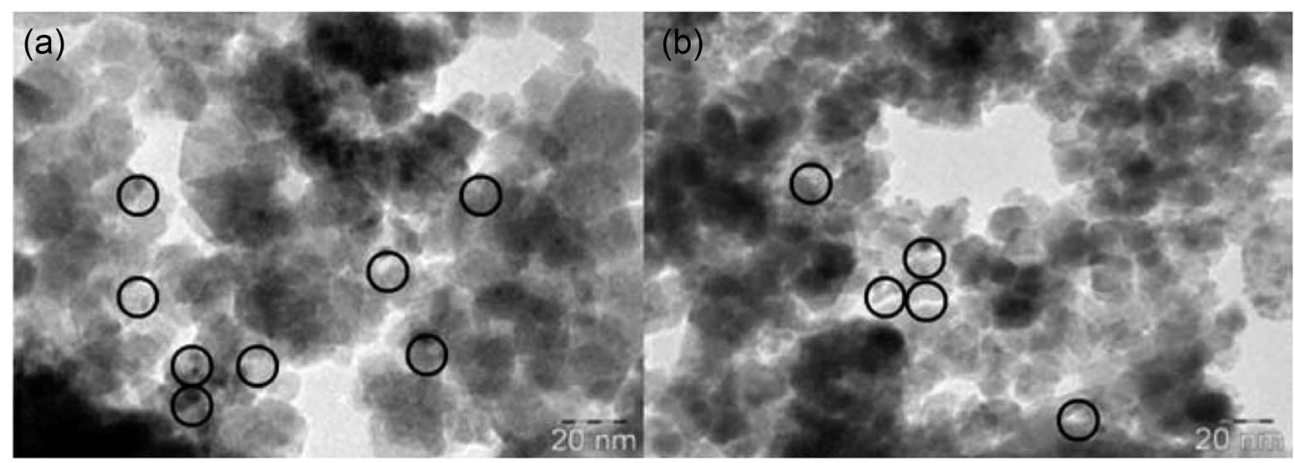

Fig. 5 TEM images of $\mathrm{Pd} / \mathrm{Fe}_{3} \mathrm{O}_{4}$ nanoparticles before (a) and after (b) catalysis observed at $120 \mathrm{kV}$.

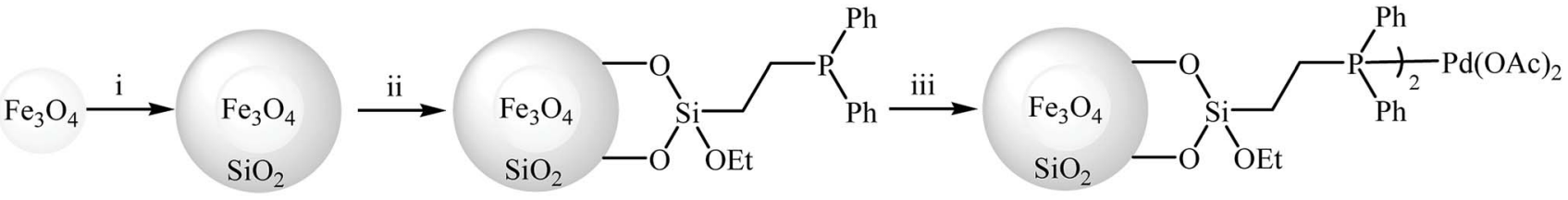

$$
\begin{aligned}
& \text { (i) }=\mathrm{Si}(\mathrm{OEt})_{4} \text {; (ii) }=\mathrm{Ph}_{2} \mathrm{PCH}_{2} \mathrm{CH}_{2} \mathrm{Si}(\mathrm{OEt})_{3} / \text { toluene; (iii) } \mathrm{Pd}(\mathrm{OAc})_{2} / \mathrm{THF} \\
& \text { PF-SiO } 2 @ \mathrm{Fe}_{3} \mathrm{O}_{4}-\mathrm{Pd}(\mathrm{OAc})_{2}
\end{aligned}
$$

Fig. 6 Schematic illustration of the preparation of $\mathrm{PF}-\mathrm{SiO}_{2}\left(\mathrm{aFe}_{3} \mathrm{O}_{4}-\mathrm{Pd}(\mathrm{OAc})_{2}\right.$.

reused for five runs with only a small decrease in the yield. Fig. 5 shows TEM images of $\mathrm{Fe}_{3} \mathrm{O}_{4}$ @PdNPs and clearly confirms that no change in the morphology took place even after five cycles. ${ }^{29}$ In a closely related investigation, Lee and co-workers also synthesized a series of biaryls through the reaction of corresponding aryl halides and phenyltrimethoxysilane using $\mathrm{Fe}_{3^{-}}$ $\mathrm{O}_{4} @ \mathrm{PdNPs} / \mathrm{KF} / \mathrm{TBAI} / \mathrm{DMA}$ as coupling system. ${ }^{30}$

Phosphine-functionalized $\mathrm{SiO}_{2} @ \mathrm{Fe}_{3} \mathrm{O}_{4}$ was employed by Zhang and co-workers for immobilizing Pd nanoparticles. The synthetic approach included preparation of $\mathrm{Fe}_{3} \mathrm{O}_{4}$-NPs $(20 \mathrm{~nm})$ coated silica $\left(\mathrm{SiO}_{2} @ \mathrm{Fe}_{3} \mathrm{O}_{4}\right)$ through a sol-gel approach followed by reaction with 2-(diphenylphosphino)ethyltriethoxysilane to

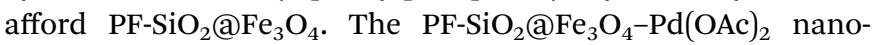

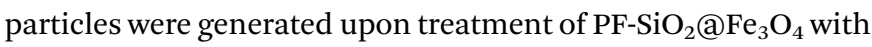

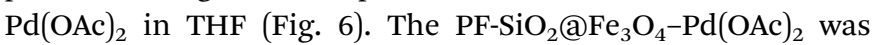
employed as an efficient and reusable catalyst for Hiyama reaction of phenyltrimethoxysilane $\mathbf{4}$ with aryl halides $\mathbf{2 5}$ in THF. Various aryl iodides and bromides with different electron densities could be used successfully in this protocol to afford the corresponding biaryls $\mathbf{2 6}$ in high to excellent yields (Scheme 10). However, no cross-coupling product was detected when phenyltrimethylsilane was used as a coupling partner under this reaction conditions. It is noted that the catalyst could be simply recovered and reused for 10 times with no detectable deactivation. ${ }^{31}$

Very recently, the group of Karami employed $\mathrm{Fe}_{3} \mathrm{O}_{4} @ \mathrm{SiO}_{2} /$ APTMS (APTMS $=3$-aminopropyltrimethoxysilane) core-shell nanocatalyst support for stabilization of $\mathrm{Pd}(\mathrm{cdha})_{2}$ (cdha $=$ bis(2-chloro-3,4-dihydroxyacetophenone)) and developing a novel catalyst, $\mathrm{Fe}_{3} \mathrm{O}_{4} @ \mathrm{SiO}_{2} / \mathrm{APTMS} / \mathrm{Pd}(\text { cdha) })_{2}$ (Fig. 7). The authors fully characterized the structure and composition of this catalyst by using various analyses such as TEM, SEM, XRD, and FT-IR. According to the TEM images, the average sizes of $\mathrm{Fe}_{3} \mathrm{O}_{4}$ in $\mathrm{Fe}_{3} \mathrm{O}_{4} @ \mathrm{SiO}_{2} /$ APTMS and palladium in $\mathrm{Fe}_{3} \mathrm{O}_{4} @ \mathrm{SiO}_{2} /$ APTMS/Pd(cdha) $)_{2}$ nanoparticles are about $23.8 \mathrm{~nm}$ and $15.8 \mathrm{~nm}$ respectively. The utility of the catalyst, was studied for fluoride-free Hiyama cross-coupling reactions of aryl halides with phenyltrimethoxysilane. It was found that the solvent, activator, and reaction temperature could affect the process. The best results were obtained in the presence of $\mathrm{NaOH}$ /sodium dodecylsulfate (SDS) combination as the activating system at $100^{\circ} \mathrm{C}$ and water as the solvent. It should be mentioned that the

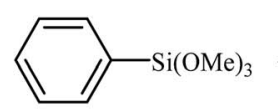

$\mathrm{X}=\mathrm{Br}$, I

$\mathrm{Y}=\mathrm{CH}, \mathrm{N}$

$\mathrm{R}=\mathrm{H}, 4-\mathrm{Me}, 4-\mathrm{OMe}, 4-\mathrm{Ac}, 4-\mathrm{F}, 4-\mathrm{Cl}, 4-\mathrm{NO}_{2}$, 3-Me, 3-OMe, 3-F, 3-NO $\mathrm{N}_{2}$, 2-Me, 2-F

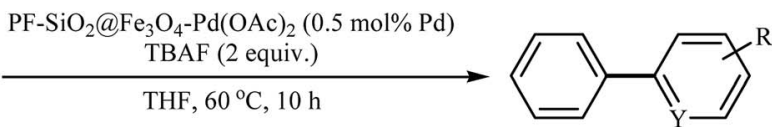

26

17 examples $(81-99 \%)$ (average yield: $93 \%$ )

Scheme $10 \mathrm{C}-\mathrm{C}$ cross-coupling of phenyltrimethoxysilane 4 with aryl halides 25 catalyzed by $\mathrm{PF}-\mathrm{SiO}_{2}\left(\mathrm{aFe}_{3} \mathrm{O}_{4}-\mathrm{Pd}(\mathrm{OAc})_{2}\right.$. 


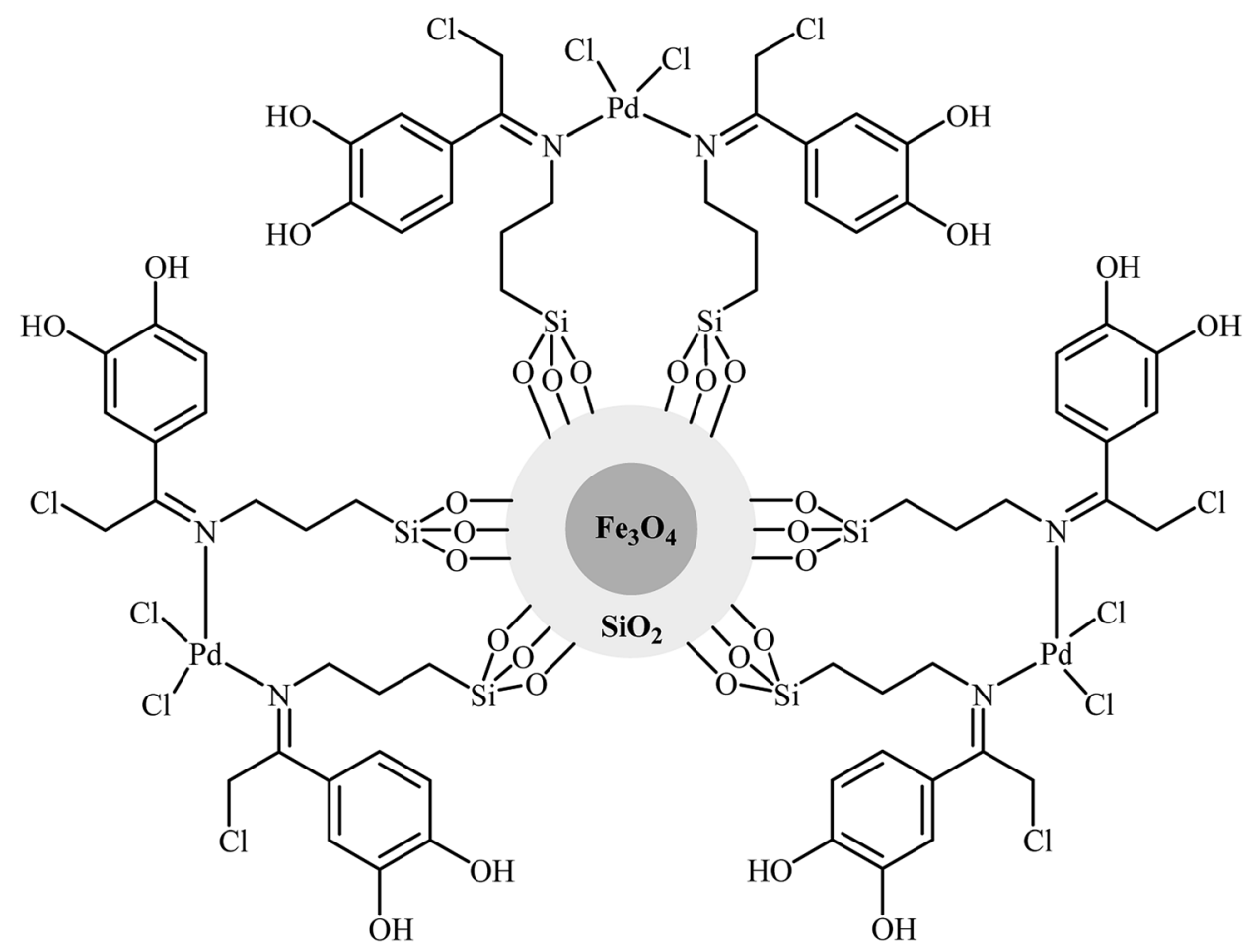

Fig. 7 Chemical structure of $\mathrm{Fe}_{3} \mathrm{O}_{4}\left(\mathrm{aSiO}_{2} / \mathrm{APTMS} / \mathrm{Pd}(\mathrm{cdha})_{2}\right.$.

catalyst was easily separated from the reaction mixture by the use of an external magnetic field and was efficiently reused for four cycles keeping almost the same activity in each cycle. ${ }^{32}$

Zinc oxide nanoparticles have recently emerged as promising supports for immobilization of metal nanoparticles. ZnOsupported palladium nanoparticles have been extensively studied for cross-coupling reactions. ${ }^{33}$ In 2015, Sarvari and Razmi synthesized ZnO-supported Pd nanoparticles through the chemical precipitation (CP) method. The method involves the reaction of $\mathrm{Pd}\left(\mathrm{NO}_{3}\right)_{2}$ and $\mathrm{Zn}\left(\mathrm{NO}_{3}\right)_{2}$ in aqueous solution of $\mathrm{Na}_{2} \mathrm{CO}_{3}(1 \mathrm{M})$ for $2 \mathrm{~h}$ and then filtration of the resulted precipitate. The catalytic activity of heterogeneous nano $\mathrm{Pd} / \mathrm{ZnO}$ catalyst was studied for Hiyama coupling reaction between phenyl trimethoxysilane $\mathbf{4}$ and aryl halides $\mathbf{2 7}$ in the presence of $\mathrm{K}_{2} \mathrm{CO}_{3}$ as a base in ethyleneglycol. The corresponding biaryls 28 were obtained in high to excellent yields (Scheme 11). The catalytic system was also efficient in the Suzuki-Miyaura cross- coupling reaction. Furthermore, it could be reused ten times without obvious decrease of the catalytic activity. ${ }^{34}$

Very recently, in a related investigation, the same research team described that the Hiyama coupling reaction of phenyl trimethoxysilane with aryl halides in the presence of $\mathrm{Pd} / \mathrm{ZnO}$ $\mathrm{NPs} / \mathrm{Cs}_{2} \mathrm{CO}_{3}$ combination as a catalytic system under visiblelight irradiation at room temperature produced the desired biaryls in good yields. ${ }^{35}$

In 2018, Bazgir and his team developed a novel heterogeneous catalyst (Pd@DCA-MCM; DCA-MCM = 1,2-dicarboxylic acid-functionalized MCM-41) via a four-step procedure through the reaction of MCM-41 with 2-(trimethoxylsilyl)ethane-1-thiol and subsequent reaction of resulted MCM-SH with maleic anhydride followed by hydrolysis at $80^{\circ} \mathrm{C}$ and finally reaction of prepared MCM-DCA with an acetonitrile solution of palladium acetate at room temperature (Scheme 12). ${ }^{36}$ The catalyst has been characterized by FT-IR, TGA, XRD, AAS, TEM, SEM, and
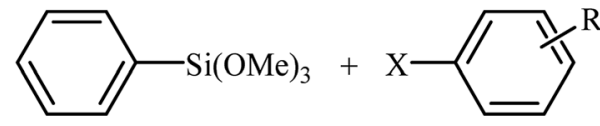

4, (1 mmol)

$\mathrm{X}=\mathrm{Cl}, \mathrm{Br}, \mathrm{I}$

$\mathrm{R}=\mathrm{H}, 4-\mathrm{OMe}, 4-\mathrm{NO}_{2}, 4-\mathrm{NH}_{2}, 4-\mathrm{CN}, 4-\mathrm{Ac}, 2-\mathrm{Me}$

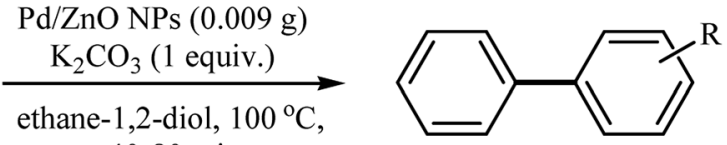

40-80 $\mathrm{min}$

28

(average yield: $92 \%$ )

Scheme 11 Synthesis of functionalized biaryls 28 through Pd/ZnO NPs-catalyzed reaction of phenyl trimethoxysilane 4 and aryl halides 27 in ethyleneglycol. 

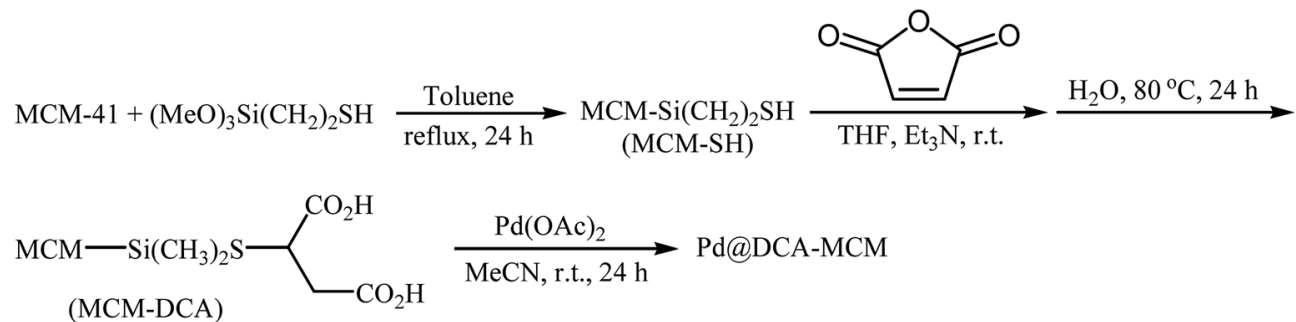

Scheme 12 Synthesis route for the preparation of PdaDCA-MCM.

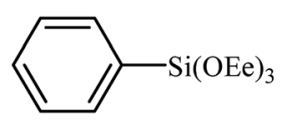

14

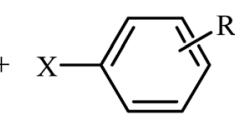

29

$\mathrm{X}=\mathrm{Br}, \mathrm{I}$

$\mathrm{R}=\mathrm{H}, 4-\mathrm{Me}, 4-\mathrm{OMe}, 4-\mathrm{COMe}, 4-\mathrm{NO}_{2}$

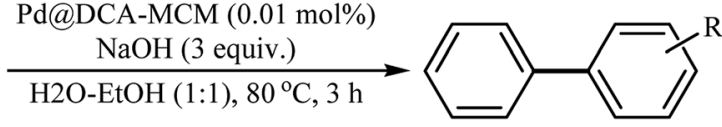

30

(average yield: $89 \%$ )

Scheme 13 (Pd@DCA-MCM)-catalyzed coupling of triethoxy(phenyl)silane 14 and aryl halides 29.

EDS measurements. The size of the palladium nanoparticles was found to be 10-12 nm by TEM technique. The Pd@DCAMCM nanocomposite exhibited a high catalytic activity in the Hiyama cross-coupling reaction of triethoxy(phenyl)silane 14 and aryl halides 29 in $\mathrm{H}_{2} \mathrm{O}-\mathrm{EtOH}(1: 1)$ under fluoride-free conditions. The results showed that the corresponding biaryls 30 were readily formed in excellent yields after $3 \mathrm{~h}$ (Scheme 13). The catalyst was also successfully employed for Suzuki and Sonogashira cross-coupling reactions. The reusability of the catalyst was investigated in the Suzuki reaction of phenylboronic acid and phenyl iodide. The catalyst could be reused five times without observable loss of activity.

Most recently, Kandathil and co-workers reported the synthesis of palladium nanoparticles through a green approach by using an aqueous-ethanolic extract of black pepper (Piper nigrum) (Fig. 8). ${ }^{37}$ The formation of Pd NPs was confirmed by various analytical techniques like XRD, FE-SEM, EDS, TEM, ATR-IR, UV-Vis spectroscopy, BET, TGA and ICP-
OES analysis. The attenuated total reflectance infrared spectroscopy (ATR-IR) revealed that functional groups like $-\mathrm{OH}$, $-\mathrm{NH}$, aromatic and aliphatic $-\mathrm{CH},-\mathrm{C}=\mathrm{O}$ and $-\mathrm{C}=\mathrm{C}$ in the biomolecules (e.g., phenols, acids, pellitorine, ethyl piperonyl cyanoacetate, piperine and $N$-isobutyl-tetradeca-2,4dienamide) had the most affinity for binding to $\operatorname{Pd}(\mathrm{II})$, and thereby reducing it to $\operatorname{Pd}(0)$ and forming of Pd NPs. The biosynthesized Pd NPs were successfully employed as catalysts for the synthesis of a wide range of biaryls 32 via Hiyama crosscoupling of phenyl trimethoxysilane $\mathbf{4}$ and aryl halides $\mathbf{3 1}$ in the presence of $\mathrm{NaOH}$ in ethylene glycol at $100{ }^{\circ} \mathrm{C}$. This protocol furnished the functionalized biaryls with use of a very low amount of catalyst $(0.2 \mathrm{~mol} \%)$ in excellent to almost quantitative yields (Scheme 14) with no need to any fluoride source. Interestingly, the Pd NPs could be easily from the final reaction mixture by centrifugation (6000 rpm for $15-30 \mathrm{~min}$ ), and then be reused up to ten times without considerable loss in the catalytic activity.

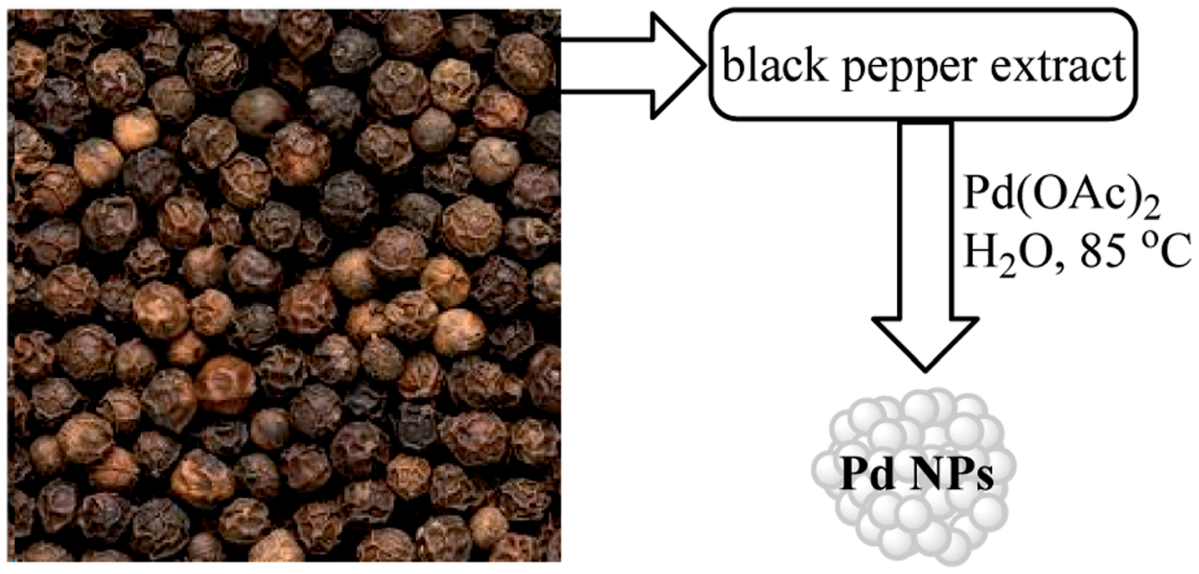

Fig. 8 Kandathil's synthesis of Pd NPs. 


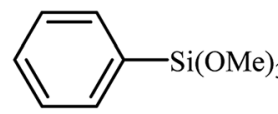

4

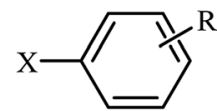

31

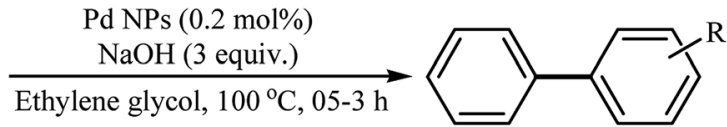

32

$\mathrm{X}=\mathrm{Br}, \mathrm{I}$

$\mathrm{R}=\mathrm{H}, 4-\mathrm{Me},{ }^{4}{ }^{\mathrm{t}} \mathrm{Bu}, 4-\mathrm{COMe}, 4-\mathrm{COPh}, 4-\mathrm{CHO}, 4-\mathrm{CO}_{2} \mathrm{H}, 4-\mathrm{OH}$, 4-CN, 4- $\mathrm{NO}_{2}, 4-\mathrm{NH}_{2}, 3-\mathrm{CO}_{2} \mathrm{H}, 2-\mathrm{CHO}, 2,4-\mathrm{F}_{2}, 3-\mathrm{F}-4-\mathrm{NH}_{2}$

21 examples $(87-98 \%)$

(average yield: 93\%)

Scheme 14 Pd NPs-catalyzed Hiyama cross-coupling of phenyl trimethoxysilane 4 and aryl halides 31.

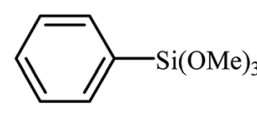

4

$\mathrm{X}=\mathrm{Cl}, \mathrm{Br}, \mathrm{I}$

$\mathrm{R}=\mathrm{H}$, 4-OMe, 4-NO 2 , 4-COMe, 4-CHO, 4-Br, 3-Me, 2-COMe

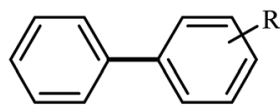

34

10 examples (35-92\%) (average yield: $81 \%$ )

Scheme 15 Au-NPsaXAD-4 catalyzed synthesis of biaryls 34 from phenyl trimethoxysilane 4 and aryl halides 33.

2.1.2. Gold. Gold nanoparticles catalyzed Hiyama crosscoupling reaction of aryl siloxanes with aryl halides has been scarcely studied; in fact, only one example of such a reaction was reported in the literature. In this report, Shah and Kaur synthesized a range of biaryls $\mathbf{3 4}$ through treatment of phenyl trimethoxysilane $\mathbf{4}$ with various aryl halides $\mathbf{3 3}$ using catalytic amounts of Amberlite XAD-4 resin supported gold nanoparticles $(3-8 \mathrm{~nm})$ in ethanol/water mixture. The reaction was carried out under microwave irradiation and immediately provided the desired biaryls $\mathbf{3 4}$ in moderate to excellent yields (Scheme 15). The decreasing order of reactivity for aryl halides is $\mathrm{Ar}-\mathrm{I}>\mathrm{Ar}-\mathrm{Br}>\mathrm{Ar}-\mathrm{Cl}$. Notably, the catalyst was easily separated from the reaction medium and reused for the next four runs without significant loss of activity. ${ }^{6}$

2.1.3. Nickel. Very recently, Hajipour and Abolfathi designed a novel triazole-functionalized $\mathrm{SiO}_{2} @ \mathrm{Fe}_{3} \mathrm{O}_{4}$ support for the immobilization of nickel nanoparticle via a five-step procedure through silica encapsulation of $\mathrm{Fe}_{3} \mathrm{O}_{4}$ NPs and subsequent reaction with trimethoxy (vinyl) silane and then oxidization using $\mathrm{H}_{2} \mathrm{O}_{2}$ followed by ring-opening of the oxirane rings through reaction with sodium azide and finally reaction with 2-ethynylpyridine via click reaction (Fig. 9). The immobilization of nickel nanoparticle was carried out by the reduction of $\mathrm{NiCl}_{2} \cdot 6 \mathrm{H}_{2} \mathrm{O}$ in the presence of $\mathrm{N}_{2} \mathrm{H}_{4}$ as reducing agent. The morphology observed by TEM images revealed the core-shell structure of nanoparticles and DLS analysis showed that the nanoparticles have sizes of around $14 \mathrm{~nm}$. The obtained catalyst, TF- $\mathrm{SiO}_{2} @ \mathrm{Fe}_{3} \mathrm{O}_{4}-\mathrm{Ni}$ was found to be an efficient and reusable catalyst in the synthesis of biaryls 36 through fluoride-free Hiyama cross-coupling of phenyltrimethoxysilane 4 with (het)aryl halides 35 in binary solvent water/EtOH with ratio 1: 1 (Scheme 16). The catalyst could be recovered by an external magnet, and further reused for more than six consecutive times without significant loss of activity. ${ }^{38}$

\subsection{Bimetalic nanoparticles}

Recently, bimetallic nanoparticle catalysts have drawn intense attention because of their great catalytic performance ${ }^{39}$ and low production costs. ${ }^{40}$ Accordingly, a huge variety of bimetallic nanoparticles have been prepared and applied as catalysts for carbon-carbon cross-coupling reactions ${ }^{41}{ }^{41}$ In this section, we will give a general overview of the recent advances in bimetallic nanoparticle catalyzed Hiyama cross-coupling reactions.

2.2.1. Pd-Ni NPs. One of the earliest reports of the applicability of Pd/Ni bimetallic nanoparticle catalysts in Hiyama cross-coupling reactions, has been reported by Pachón and coworkers in 2005, when phenyl trimethoxysilane 4 underwent coupling reaction with aryl halides 37 in the presence of $1 \mathrm{~mol} \%$ of core-shell Ni-Pd clusters ( $0.1 \mathrm{mmol} \mathrm{Ni}$ and $0.01 \mathrm{mmol} \mathrm{Pd})$ with a mean diameter of $4.9 \mathrm{~nm}$ and 1.5 equiv., of TBAF in THF to form corresponding biaryls 38 (Scheme 17). Various aryl bromides and iodides were used to establish the general applicability of the method. Interestingly, this Pd/Ni NPs catalyzed coupling reaction is equally effective for both the electronrich and electron-poor aryl iodides. In the cases of aryl bromides, the substrates bearing electron-withdrawing substituents gave higher yields than those bearing electrondonating substituents. It should be mentioned that this catalyst has been synthesized through the combination of electrochemical and wet chemical techniques. ${ }^{42}$

A decade later, the group of Nájera investigated bimetallic palladium-nickel nanoparticle catalyst supported on multiwall carbon nanotubes with varying $\mathrm{Pd}$ to $\mathrm{Ni}$ atomic ratios for Hiyama coupling of phenyl trimethoxysilane 4 with 4-iodoanisole 39 in the absence of a fluoride source in water (Table 2). An almost quantitative yield of expected biaryl $\mathbf{4 0}$ was obtained with $\mathrm{Pd}_{70} \mathrm{Ni}_{30} / \mathrm{MWCNTs}$. Notably, the same results were also obtained by using monometallic Pd NPs supported in MWCNTs as the catalyst. The bimetallic Ni-Pd nanoparticle catalysts were also examined for the Hiyama, Heck and Sonogashira reactions. 


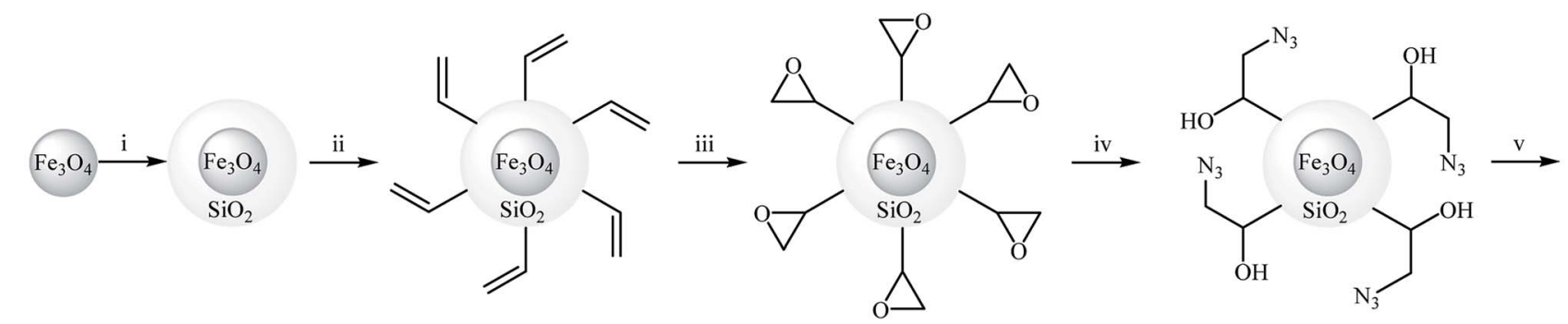<smiles>CC(O)Cn1cc(-c2ccccn2)nn1</smiles><smiles>CC(O)Cn1cc(-c2ccccn2)nn1</smiles><smiles></smiles>

$\mathrm{TF}_{-} \mathrm{SiO}_{2} @ \mathrm{Fe}_{3} \mathrm{O}_{4}-\mathrm{Ni}$

(i) = TEOS; (ii) $=\mathrm{CH}_{2} \mathrm{CHSi}(\mathrm{OEt})_{3}, \mathrm{CHCl}_{3}$, reflux, $12 \mathrm{~h}$; (iii) $\mathrm{NaN}_{3}, \mathrm{H}_{2} \mathrm{O} / \mathrm{MeOH}, 70^{\circ} \mathrm{C}, 24 \mathrm{~h}$; (iv) $\mathrm{H}_{2} \mathrm{O}_{2}, 50{ }^{\circ} \mathrm{C}, 12 \mathrm{~h}$;

(v) 2-ethynylpyridine, $\mathrm{CuI}, \mathrm{DMF} / \mathrm{H}_{2} \mathrm{O}$, r.t., $72 \mathrm{~h}$; (vi) $\mathrm{NiCl}_{2}, 12$ h, r.t., $\mathrm{N}_{2} \mathrm{H}_{4}, 60^{\circ} \mathrm{C}, 2 \mathrm{~h}$

Fig. 9 Synthesis route of $\mathrm{TF}-\mathrm{SiO}_{2}\left(\mathrm{aFe}_{3} \mathrm{O}_{4}-\mathrm{Ni}\right.$.

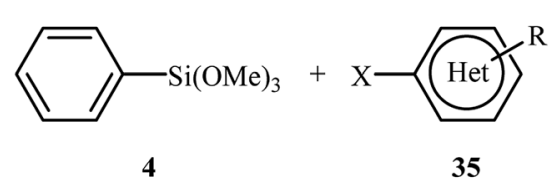

$\mathrm{X}=\mathrm{Cl}, \mathrm{Br}, \mathrm{I}$

Het $=$ phenyl, pyridyl, and thienyl derivatives

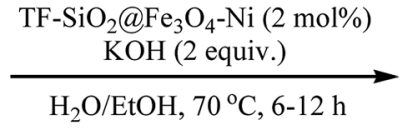

, $70{ }^{\circ} \mathrm{C}, 12 \mathrm{~h}$

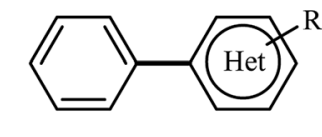

36

17 examples $(54-97 \%)$

(average yield: $85 \%$ )

Scheme $16 \mathrm{TF}-\mathrm{SiO}_{2}\left(\mathrm{aFe}_{3} \mathrm{O}_{4}-\mathrm{Ni}\right.$ catalyzed synthesis of biaryls 36 in $\mathrm{H}_{2} \mathrm{O} / \mathrm{EtOH}$.

Table 2 Comparison of the catalytic activity of several bimetallic palladium-nickel nanoparticle catalysts in Hiyama cross-coupling reaction of trimethoxyphenylsilane 4 with 4-iodoanisole 39

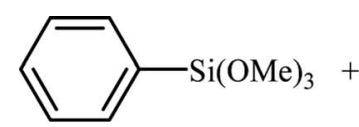

4<smiles>COc1ccc(I)cc1</smiles>

39 $\underset{50 \% \mathrm{NaOH}(2.5 \text { equiv. })}{\stackrel{\text { cat. }(0.1 \mathrm{~mol} \% \mathrm{Pd})}{\longrightarrow}}$

$120{ }^{\circ} \mathrm{C}$

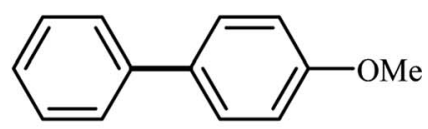

40

\begin{tabular}{|c|c|c|c|c|}
\hline Entry & Cat. & $\begin{array}{l}\mathrm{PhSi}(\mathrm{OMe})_{3} \\
\text { (equiv.) }\end{array}$ & Time (h) & Yield (\%) \\
\hline 1 & Pd/MWCNTs & 1.5 & 3 & 95 \\
\hline 2 & $\mathrm{Pd}_{70} \mathrm{Ni}_{30} /$ MWCNTs & 1.5 & 3 & 96 \\
\hline 3 & Pd/MWCNTs & 1.5 & 1 & 95 \\
\hline 4 & $\mathrm{Pd}_{70} \mathrm{Ni}_{30} / \mathrm{MWCNTs}$ & 1.5 & 1 & 92 \\
\hline 5 & Pd/MWCNTs & 1.2 & 1 & 85 \\
\hline 6 & $\mathrm{Pd}_{70} \mathrm{Ni}_{30} /$ MWCNTs & 1.2 & 1 & 77 \\
\hline 7 & $\mathrm{Pd}_{50} \mathrm{Ni}_{50} /$ MWCNTs & 1.2 & 1 & 76 \\
\hline 8 & $\mathrm{Pd}_{30} \mathrm{Ni}_{70} /$ MWCNTs & 1.2 & 1 & 82 \\
\hline
\end{tabular}




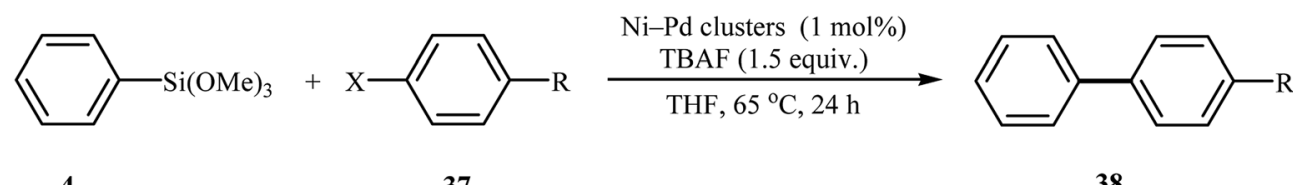

$$
\begin{aligned}
& \mathrm{X}=\mathrm{Br}, \mathrm{I} \\
& \mathrm{R}=\mathrm{H}, \mathrm{Me}, \mathrm{OMe}, \mathrm{NO}_{2}, \mathrm{NH}_{2}, \mathrm{CF}_{3}
\end{aligned}
$$

Scheme 17 Palladium-coated nickel nanoclusters catalyzed synthesis of biaryls 38 reported by Pachón.

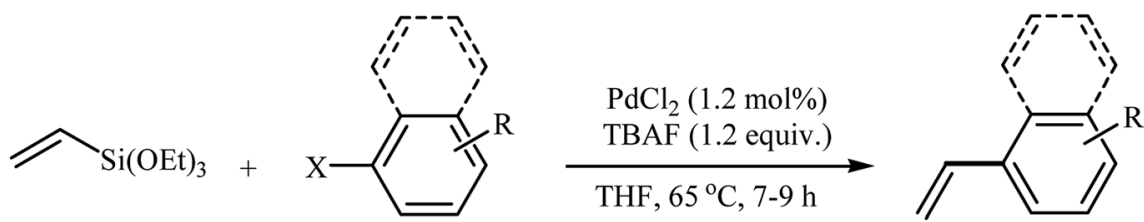

41

42

15 examples (67-90\%)

(average yield: 78\%)

43

$\mathrm{X}=\mathrm{Br}, \mathrm{I}$

$\mathrm{R}=\mathrm{H}, 4-\mathrm{OMe}$, 4-CHO, 4-Ac, 4- $\mathrm{CO}_{2} \mathrm{Et}, 4-\mathrm{CN}, 4-\mathrm{NO}_{2}$, 4-Br, 4-I, 4-CONHPh, 4-NHCOPh, 3-Ac, 3- $\mathrm{NO}_{2}$

Scheme 18 Synthesis of styrenes 43 via PdNPs-catalyzed coupling of triethoxyvinylsilane 41 with corresponding aryl halides 42.

Excellent yields were obtained for these coupling reactions using $\mathrm{Ni}_{50} \mathrm{Pd}_{50} / \mathrm{MWCNTs}$ catalyst at $120{ }^{\circ} \mathrm{C}$ in water. ${ }^{43}$

2.2.2. Pd-Au NPs. In 2014, the group of Zhu found that addition of a plasmonic component to the Pd catalyst and irradiation with visible light improves the yields of carboncarbon and carbon-heteroatom cross-coupling reactions such as Sonogashira, Hiyama, Stille, and Buchwald-Harwing reactions. They showed that nanoparticles derived from palladium and gold (Au-Pd allot NPs) efficiently catalyzed the Hiyama coupling of phenyl trimethoxysilane with 3-methylphenyl iodide under visible light irradiation and gave the coupling product in a $71 \%$ yield. The same process in the dark gave only $7 \%$ yield. The authors performed DFT calculations to shed light on the reaction mechanism. The results indicate that transfer of the light excited electrons from the alloy NPs surface to the reactant molecules adsorbed on the NPs surface activates the reactants. $^{44}$

\section{Coupling of vinylsilanes with aryl halides}

In 2011, Chatterjee, Dey, and Ranu have described the synthesis of functionalized styrenes $\mathbf{4 3}$ through the Hiyama crosscoupling of triethoxyvinylsilane $\mathbf{4 1}$ with corresponding aryl halides 42 catalyzed by $\operatorname{Pd}(0)$ nanoparticles $(2-3 \mathrm{~nm})$ generated in situ in the reaction mixture in presence of $\mathrm{PdCl}_{2}$ and TBAF in refluxing THF $\left(65^{\circ} \mathrm{C}\right)$. The author suggested that TBAF playing a dual role in this reaction; the fluoride supplier and the nanoparticle stabilizer. Under the optimized conditions, the reaction tolerated a range of base-sensitive functional groups (COOR, CONHPh, NHCOPh, CN) and provided the coupling products in good to high yields (Scheme 18). Noteworthy, styrenyl-, cinnamyl- and dienyl-halides have also been employed as viable electrophilic partners in this cross-coupling reaction and provided corresponding trans aryl 1,3-, 1,4- and 1,5-dienes in high yields and excellent stereoselectivity. It should be mentioned that the attempts to recycle the catalyst were not successful as after the first cycle the nanoparticles grew bigger (10-15 nm), leading to lower yields and being less efficient. ${ }^{45}$ Later, Grirrane and co-workers compared the catalytic activity of several solid supported palladium nanoparticles ( $\mathrm{Pd} / \mathrm{MgO}, \mathrm{Pd} /$ $\mathrm{TiO}_{2}, \mathrm{Pd} / \mathrm{CeO}_{2}$ and $\mathrm{Pd} / \mathrm{C}$ ) for the Hiyama C-C coupling reaction of a range of aryl iodides and vinylsilanes using ligand-free conditions in DMF. The results showed that the most active catalysts for this coupling reaction were those in which palladium is supported on $\mathrm{MgO}$ and $\mathrm{TiO}_{2}$. Interestingly, the analogous $\mathrm{Pt}$ and $\mathrm{Au}$ materials were inefficient to promote this reaction. ${ }^{46}$

In 2014, Planellas and co-workers prepared palladium NPs by the hydrogenation of $\mathrm{Pd}(\mathrm{dba})_{2}$ in the presence of a trisimidazolium iodide as the stabilizer, and studied their catalytic activity in Hiyama coupling reaction of triethoxyvinylsilane $\mathbf{4 1}$ with aryl iodides $\mathbf{4 4}$ in binary solvent toluene/EtOH with ratio $1: 1$ (Scheme 19). Under optimized conditions [Pd-NPs ( $0.25 \mathrm{~mol} \% \mathrm{Pd}$ ), $\mathrm{NaOH}$ (3 equiv.), $\left.\mathrm{H}_{2} \mathrm{O} / \mathrm{MeOH}(1: 1), 100{ }^{\circ} \mathrm{C}\right]$, the desired biaryls $\mathbf{4 5}$ were obtained in moderate to almost quantitative yields. The catalyst was also highly active for Heck and copper-free Sonogashira reactions. ${ }^{47}$

Very recently, Gaikwad's group demonstrated an elegant and innovative Pd NPs-catalyzed sequential Hiyama-Heck reaction of triethoxyvinylsilane $\mathbf{4 1}$ with aromatic diazonium salts 46 into symmetrical trans-stilbene derivatives 47 (Scheme 20). Palladium nanoparticles have been generated in situ from $\mathrm{Pd}(\mathrm{OAc})_{2}$ and Triton X-100 in water. The TEM image of the in situ 


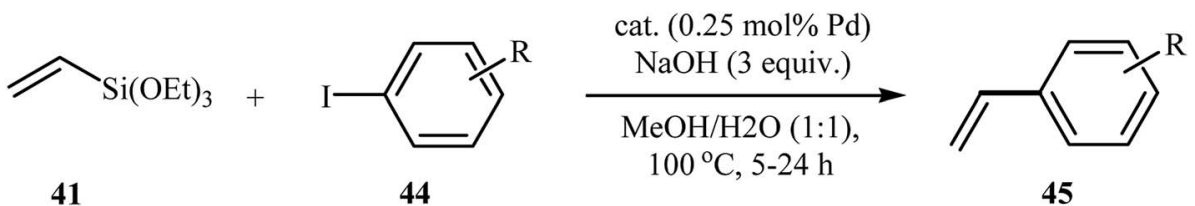

41

44

18 examples (59-97\%)

(average yield: $82 \%$ )

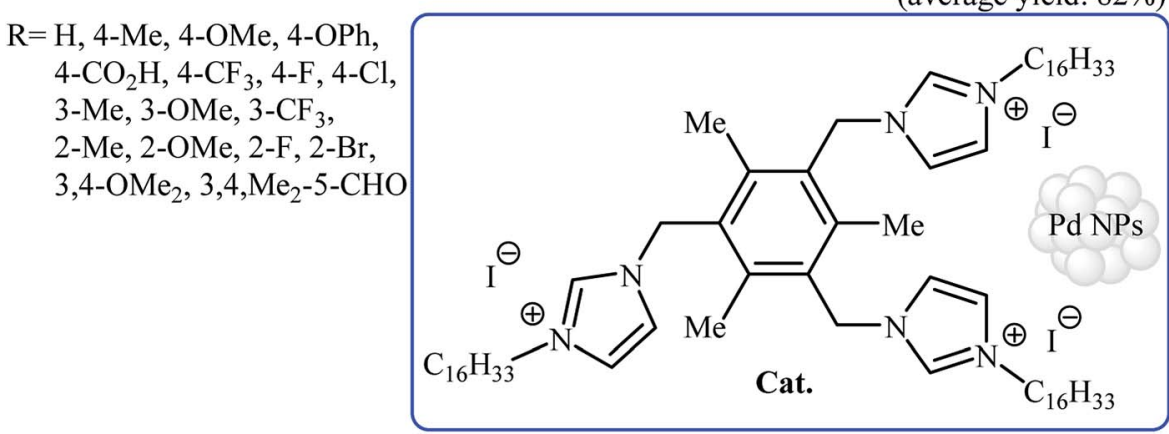

Scheme 19 PdNPs-catalyzed synthesis of styrenes 45 reported by Planellas.

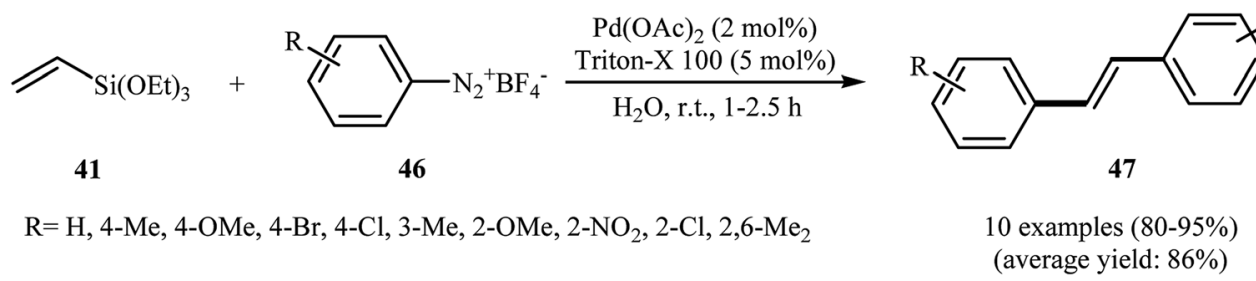

Scheme 20 Synthesis of symmetrical trans-stilbenes 47 via Pd NPs-catalyzed sequential Hiyama-Heck reaction of triethoxyvinylsilane 41 with aromatic diazonium salts 46 .

generated catalyst presented a spherical morphology of the nanoparticles with a size below $20 \mathrm{~nm}$. The results showed that the electronic nature and substitution of the diazonium salt did not affect the reaction outcome as yields of the stilbene products obtained a range from $80-95 \%$ for the 10 reactions highlighted. After the reaction, aqueous system containing the surfactant along with the Pd NPs was recovered and reused for five runs without any significant loss of catalytic activity. The author proposed reaction mechanism is depicted in Scheme $21 .^{48}$

\section{Miscellaneous reactions}

In 2008, the Ranu group reported an elegant in situ-generated palladium(0) nanoparticles catalyzed cross-coupling reaction of aryl and vinyl siloxanes 48 with allyl acetates 49 into stereoselective (E)-coupling products $\mathbf{5 0}$ employing $\mathrm{PdCl}_{2} /$ tetrabutyl ammonium bromide (TBAB) as a catalytic system in THF (Scheme 22). The reactions were generally highly stereoselective, and (E)-coupling products were obtained both from cis and trans allyl acetates. Notably, the $\operatorname{Pd}(0)$ nanoparticles could be recovered and then reused up to three times with only a small loss of catalytic activity. However, the catalyst could not perform well for fourth run and a steep loss in the product yield of approximately $60 \%$ (after 3rd run) and 20\% (after 4 th run) was observed. ${ }^{49}$
Following this work, Sarkar and his group were able to demonstrate that in situ generated Pd nanoparticles (by heating $0.04 \mathrm{mmol}$ of $\mathrm{K}_{2} \mathrm{PdCl}_{4}$ and $1.16 \mathrm{mmol}$ of PEG-600 at $70{ }^{\circ} \mathrm{C}$ for 15 min) could efficiency catalyze Hiyama coupling reaction of aryl siloxanes $\mathbf{5 1}$ with benzyl halides $\mathbf{5 2}$ to the corresponding diarylmethanes 53 in high to excellent yields (Scheme 23). The reaction showed excellent functional group tolerance and could be applied for the synthesis of a diverse range of functionalized diarylmethanes with potential biological activities..$^{50}$

Recently, Song and co-workers developed an in situ-generated Pd-NPs $(2.69 \pm 0.83 \mathrm{~nm})$ catalyzed three-component coupling reaction of trimethoxyallylsilane 54, chloromethyl(heter)oarenes 55, and carbon dioxide, which allowed for the synthesis of $\alpha, \beta$-unsaturated esters $\mathbf{5 6}$ in good to high yields (Scheme 24). This carboxylative coupling reaction took place under mild reaction conditions (1.0 MPa pressure of $\mathrm{CO}_{2}$ and $50{ }^{\circ} \mathrm{C}$ temperature) in the presence of $5 \mathrm{~mol} \%$ of $\mathrm{Pd}(\mathrm{acac})_{2}$ as a precatalyst and 2 equiv. of TBAF as an additive in DMF and tolerated considerable functionality. The additive (TBAF) played key dual roles in this reaction; the stabilizer and the activator. According to the author proposed mechanism, the reaction proceeded via an oxidative addition/transmetalation/ coordination/nucleophilic addition/reductive elimination/ isomerization sequential process. ${ }^{51}$ 


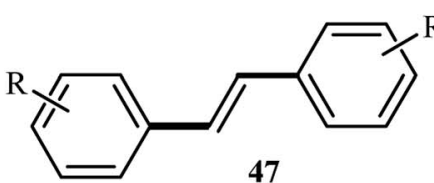

47<smiles>[R]c1ccc([R16])cc1</smiles>

A

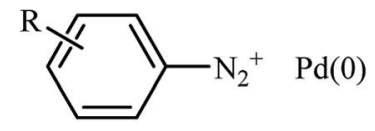

46
$\operatorname{Pd}(\mathrm{II})$

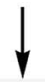

$\operatorname{Pd}(0)$
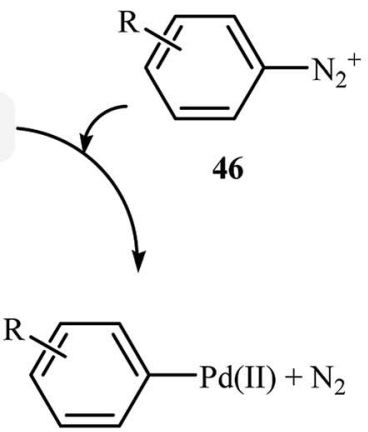

A

C

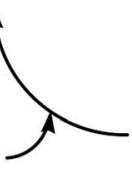

(1)

B

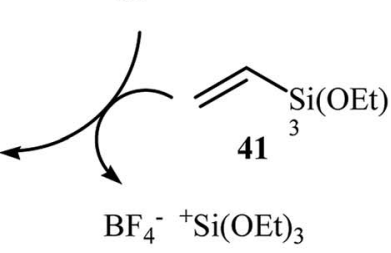

or

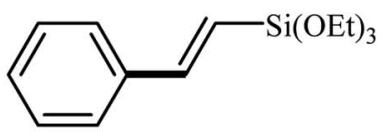

$\mathbf{B}^{\prime}$

Scheme 21 Plausible mechanism for Pd-NPs-catalyzed sequential Hiyama-Heck reaction.

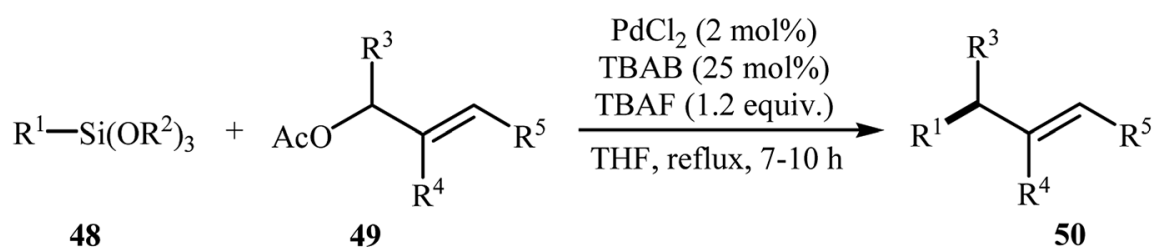

$\mathrm{R}^{1}=\mathrm{Ph}$, Tol, vinyl

18 examples $(70-85 \%)$

$\mathrm{R}^{2}=\mathrm{Me}, \mathrm{Et}$

$\mathrm{R}^{3}=\mathrm{H}, 4-\mathrm{Me}-\mathrm{C}_{6} \mathrm{H}_{4}, 4-\mathrm{Cl}-\mathrm{C}_{6} \mathrm{H}_{4}$

(average yield: $76 \%$ )

$\mathrm{R}^{4}=\mathrm{H}, \mathrm{CO}_{2} \mathrm{Me}, \mathrm{CO}_{2}{ }^{n} \mathrm{Bu}$

$\mathrm{R}^{5}=\mathrm{H}, \mathrm{Ph}, 4-\mathrm{Me}-\mathrm{C}_{6} \mathrm{H}_{4}, 4-\mathrm{Cl}-\mathrm{C}_{6} \mathrm{H}_{4}, 2-\mathrm{OMe}-\mathrm{C}_{6} \mathrm{H}_{4}$

Scheme 22 PdNPs-catalyzed cross-coupling reaction of aryl and vinyl siloxanes 48 with allyl acetates 49 developed by Ranu.

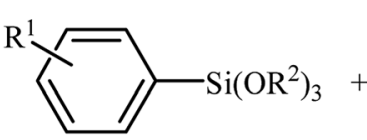

51

$\mathrm{X}=\mathrm{Br}, \mathrm{Cl}$

$\mathrm{R}^{1}=\mathrm{H}, 4-\mathrm{Me}, 4-\mathrm{OMe}$

$\mathrm{R}^{2}=\mathrm{Me}, \mathrm{Et}$

Het $(\operatorname{aryl})=$ phenyl, anphthyl, and pyridyl derivatives

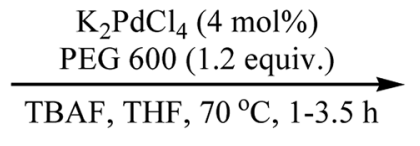

52<smiles>[R]#CC=C(Cc1ccccc1)Cc1ccccc1</smiles>

53

27 examples (78-95\%) (average yield: 85\%)

Scheme 23 Synthesis of diarylmethanes 53 via PdNPs-catalyzed Hiyama coupling of aryl siloxanes 51 with benzyl halides 52. 

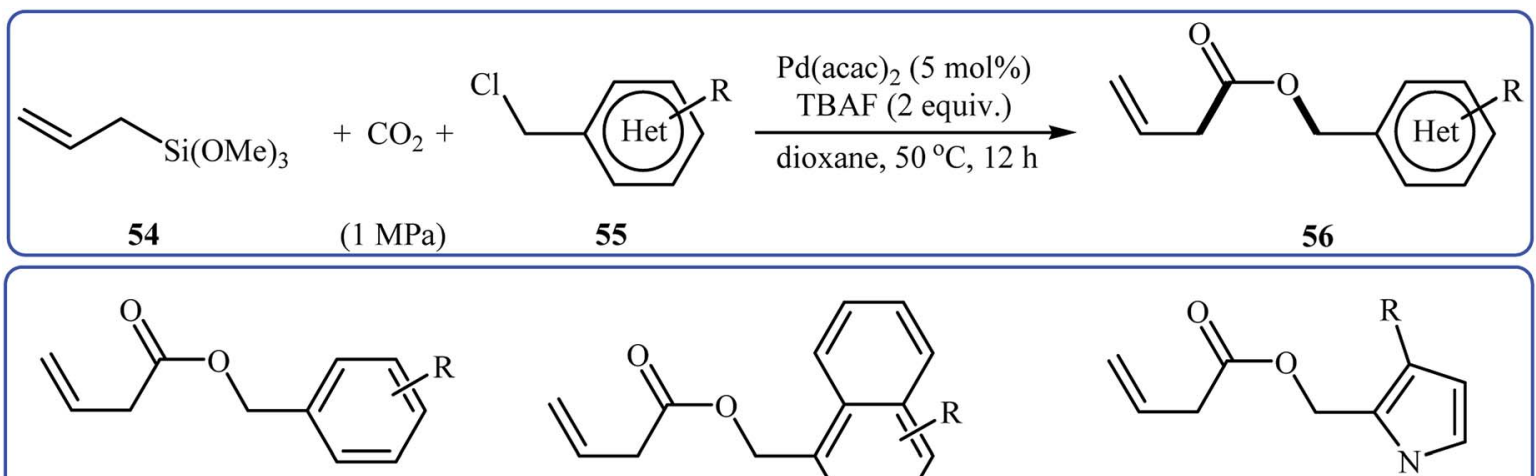

56a, R= H; (81\%)

56b, $\mathrm{R}=4-\mathrm{Me} ;(82 \%)$

56c, $\mathrm{R}=4-\mathrm{OMe} ;(88 \%)$

56d, R=4-Ph; (77\%)

56e, $\mathrm{R}=4-\mathrm{F} ;(79 \%)$

56f, $\mathrm{R}=4-\mathrm{Cl} ;(80 \%)$

56g, $\mathrm{R}=4-\mathrm{Br} ;(76 \%)$

56h, $\mathrm{R}=4-\mathrm{NO}_{2} ;(61 \%)$

56i, $\mathrm{R}=4-\mathrm{CO}_{2} \mathrm{Me} ;(69 \%)$

56j, R=3-OMe; (76\%)

56k, R=2-OMe; (77\%)

561, $\mathrm{R}=2$-OEt; $(69 \%)$

56m, R=2-Cl; (74\%)

56n, $\mathrm{R}=2,4-\mathrm{Cl}_{2} ;(71 \%)$

56o, $\mathrm{R}=3,4-\mathrm{Cl}_{2} ;(73 \%)$

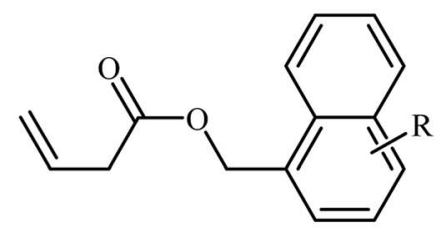

56p, $\mathrm{R}=\mathrm{H}$; $(84 \%)$

56q, R=2-Me; $(78 \%)$

56r, $\mathrm{R}=2$-OMe; $(74 \%)$

56s, $\mathrm{R}=4-\mathrm{Me}$; $(80 \%)$

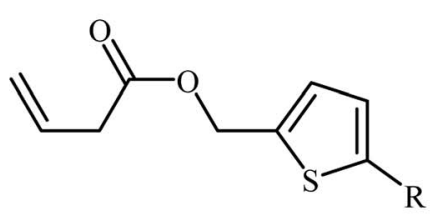

56t, $\mathrm{R}=\mathrm{H}$; $(73 \%)$

56u, R= Br; (76\%)

$\mathbf{5 6} \mathbf{v}, \mathrm{R}=$ phenylacetylene; $(71 \%)$

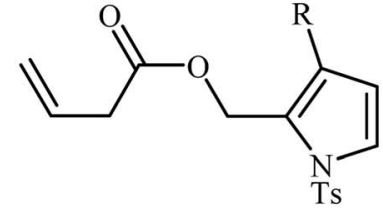

56w, R= H; $(68 \%)$

$\mathbf{5 6 x}, \mathrm{R}=\mathrm{Br} ;(65 \%)$

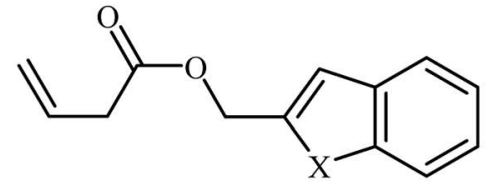

56y, $X=\mathrm{S} ;(69 \%)$

56z, $X=\mathrm{O}$; $(61 \%)$

56aa, $X=$ NTs; $(71 \%)$

Scheme 24 PdNPs-catalyzed carboxylative coupling of trimethoxyallylsilane 54 with chloromethyl(heter)oarenes 55 reported by Song et al.

\section{Conclusion}

Transition-metal-catalyzed carbon-carbon cross-coupling reactions have emerged as the most efficient methodologies for the syntheses of many molecules ranging from pharmaceuticals to material science to optical devices. Among the various carboncarbon cross-coupling reactions, Heck, Stille, Negishi, Sonogashira, Suzuki, Hiyama, and Kumada-Corriu reactions find maximum application in industrial processes. Undoubtedly, Hiyama cross-coupling of low-cost, non-toxic, and easily available organosilane reagents in comparison to the Suzuki, Negishi, Stille, and Kumada-Corriu coupling reactions is an environment-friendly protocol for the formation of the new $\mathrm{C}-\mathrm{C}$ bonds. However, silicon-based cross-coupling reactions often require heating in the presence of a fluoride source (e.g. CsF, KF, AgF, TBAF, TBAT, and TASF) which has significantly hampered their widespread acceptance. To address the "fluoride problem", recently, several metal-based nanocatalysts have been developed that due to their very high surface-to-volume ratio compared to bulk catalytic materials and reactive morphologies allow for fluoride-free Hiyama coupling under relatively mild conditions, with the benefits of high product yield, low catalyst loading, and ease of catalyst separation. As illustrated, most of the nanoparticles catalyzed Hiyama coupling reactions covered in this review could be easily achieved in the most environmentally benign solvent, water. These results clearly show the potential application of these reactions in industry. Despite the significant and revolutionary achievements during the past few years in this research arena, many challenges still remain to be overcome: (a) the number of reported examples in some reactions such as coupling of vinylsilanes with aryl halides/aromatic diazonium salts and coupling of aryl siloxanes with benzyl/alkyl halides are narrow and there is further need to study the scope and limitations of these reactions; (b) most of the nanoparticle catalyzed Hiyama reactions are limited to the use of monometallic catalysts. Thus the exploration of bi-metallic, tri-metallic, and multi-metallic nanoparticles (BNPs, TNPs, and MNPs) are highly desirable in term of the cost of preparation of the catalysts; and (c) the coupling of readily available and low-cost aryl chlorides remained challenging and more difficult than the corresponding aryl bromides and iodides. Therefore the development of truly efficient catalytic systems which can accomplish the coupling of aryl chlorides and organosilanes with high yields is strongly needed. It is our hope that this review will stimulate researchers to further research and thinking in this interesting and important research field.

\section{Conflicts of interest}

There are no conflicts to declare.

\section{References}

1 (a) N. Miyaura and A. Suzuki, Chem. Rev., 1995, 95, 24572483; (b) H. Doucet and J. C. Hierso, Angew. Chem., Int. Ed., 
2007, 46, 834-871; (c) D. Roy and Y. Uozumi, Adv. Synth. Catal., 2018, 360, 602-625.

2 (a) I. P. Beletskaya and V. P. Ananikov, Chem. Rev., 2011, 111, 1596-1636; (b) F. M. Tappe, V. T. Trepohl and M. Oestreich, Synthesis, 2010, 3037-3062; (c) M. Abdoli, Z. Mirjafary, H. Saeidian and A. Kakanejadifard, $R S C A d v$., 2015, 5, 44371-44389.

3 F. Diedrich and A. De Meijere, Metal catalyzed cross-coupling reactions, vol. 1, Wiley-VCH Verlag GmbH, Weinheim, 2004.

4 Y. Nakao and T. Hiyama, Chem. Soc. Rev., 2011, 40, 48934901.

5 (a) F. Foubelo, C. Nájera and M. Yus, Chem. Rec., 2016, 16, 2521-2533; (b) S. Sarhandi, M. Daghagheleh, M. Vali, R. Moghadami and E. Vessally, Chem. Rev. Lett., 2018, 1, 9-15.

6 D. Shah and H. Kaur, Curr. Catal., 2015, 4, 224-230.

7 V. Polshettiwar and R. S. Varma, Green Chem., 2010, 12, 743754.

8 E. Vessally, M. Babazadeh, A. Hosseinian, S. Arshadi and L. Edjlali, J. CO2 Util., 2017, 21, 491-502.

9 D. Wang and D. Astruc, Chem. Rev., 2014, 114, 6949-6985.

10 A. Fihri, M. Bouhrara, B. Nekoueishahraki, J.-M. Basset and V. Polshettiwar, Chem. Soc. Rev., 2011, 40, 5181-5203.

11 A. Balanta, C. Godard and C. Claver, Chem. Soc. Rev., 2011, 40, 4973-4985.

12 R. K. Sharma, S. Dutta, S. Sharma, R. Zboril, R. S. Varma and M. B. Gawande, Green Chem., 2016, 18, 3184-3209.

13 (a) K. Didehban, E. Vessally, A. Hosseinian, L. Edjlali and E. S. Khosroshahi, RSC Adv., 2018, 8, 291-301; (b) S. Shahidi, P. Farajzadeh, P. Ojaghloo, A. Karbakhshzadeh and A. Hosseinian, Chem. Rev. Lett., 2018, 1, 37-44; (c) S. Mohammadi, M. Musavi, F. Abdollahzadeh, S. Babadoust and A. Hosseinian, Chem. Rev. Lett., 2018, 1, 49-55.

14 (a) E. Vessally, K. Didehban, R. Mohammadi, A. Hosseinian and M. Babazadeh, J. Sulfur Chem., 2018, 39, 332-349; (b) E. Vessally, R. Mohammadi, A. Hosseinian, K. Didehban and L. Edjlali, J. Sulfur Chem., 2018, 39, 443-463; (c) F. A. H. Nasab, L. Z. Fekri, A. Monfared, A. Hosseinian and E. Vessally, RSC Adv., 2018, 8, 18456-18469; (d) K. Nejati, S. Ahmadi, M. Nikpassand, P. D. K. Nezhad and E. Vessally, RSC Adv., 2018, 8, 19125-19143; (e) A. Hosseinian, F. A. H. Nasab, S. Ahmadi, Z. Rahmani and E. Vessally, RSC Adv., 2018, 8, 26383-26398; (f) A. Hosseinian, S. Farshbaf, L. Z. Fekri, M. Nikpassand and E. Vessally, Top. Curr. Chem., 2018, 376, 23; $(g)$ A. Hosseinian, S. Ahmadi, F. A. H. Nasab, R. Mohammadi and E. Vessally, Top. Curr. Chem., 2018, 376, 39; (h) A. Hosseinian, F. A. H. Nasab, S. Ahmadi, Z. Rahmani and E. Vessally, RSC Adv., 2018, 8, 26383-26398; (i) A. Hosseinian, R. Mohammadi, S. Ahmadi, A. Monfared and Z. Rahmani, RSC Adv., 2018, 8, 33828-33844; (j) S. Sarhandi, M. Daghagheleh, M. Vali, R. Moghadami and E. Vessally, Chem. Rev. Lett., 2018, 1, 9-15; (k) A. Hosseinian, S. Farshbaf, R. Mohammadi, A. Monfared and E. Vessally, RSC Adv., 2018, 8, 17976-17988; (l) S. Farshbaf, L. Z. Fekri, M. Nikpassand, R. Mohammadi and E. Vessally, J. CO2 Util., 2018, 25, 194-204; (m)
S. Farshbaf, L. Sreerama, T. Khodayari and E. Vessally, Chem. Rev. Lett, 2018, 1, 56-67; (n) E. Vessally, A. Hosseinian, L. Edjlali, A. Bekhradnia and M. D. Esrafili, RSC Adv., 2016, 6, 71662-71675; (o) E. Vessally, L. Edjlali, A. Hosseinian, A. Bekhradnia and M. D. Esrafili, RSC Adv., 2016, 6, 49730-49746; (p) E. Vessally, A. Hosseinian, L. Edjlali, A. Bekhradnia and M. D. Esrafili, RSC Adv., 2016, 6, 99781-99793; (q) E. Vessally, S. Soleimani-Amiri, A. Hosseinian, L. Edjlali and A. Bekhradnia, RSC Adv., 2017, 7, 7079-7091.

15 J.-A. García-López and M. F. Greaney, Chem. Soc. Rev., 2016, 45, 6766-6798.

16 I. Hussain, J. Capricho and M. A. Yawer, Adv. Synth. Catal., 2016, 358, 3320-3349.

17 D. Srimani, S. Sawoo and A. Sarkar, Org. Lett., 2007, 9, 36393642.

18 B. C. Ranu, R. Dey and K. Chattopadhyay, Tetrahedron Lett., 2008, 49, 3430-3432.

19 A. Komáromi, F. Szabó and Z. Novák, Tetrahedron Lett., 2010, 51, 5411-5414.

20 J. Y. Kim, Y. Jo, S.-K. Kook, S. Lee and H. C. Choi, J. Mol. Catal. A: Chem., 2010, 323, 28-32.

21 D. Shah and H. Kaur, J. Mol. Catal. A: Chem., 2012, 359, 6973.

22 C. Diebold, A. Derible, J.-M. Becht and C. Le Drian, Tetrahedron, 2013, 69, 264-267.

23 C. Premi and N. Jain, Eur. J. Org. Chem., 2013, 5493-5499.

24 S.-H. Huang, C.-H. Liu and C.-M. Yang, Green Chem., 2014, 16, 2706-2712.

25 D. Shah and H. Kaur, Curr. Catal., 2014, 3, 39-46.

26 A. Ohtaka, T. Kotera, A. Sakon, K. Ueda, G. Hamasaka, Y. Uozumi, T. Shinagawa, O. Shimomura and R. Nomura, Synlett, 2016, 27, 1202-1206.

27 A. Sakon, R. Ii, G. Hamasaka, Y. Uozumi, T. Shinagawa, O. Shimomura, R. k. Nomura and A. Ohtaka, Organometallics, 2017, 36, 1618-1622.

28 (a) J. Govan and Y. K. Gun'ko, Nanomaterials, 2014, 4, 222241; (b) T. Cheng, D. Zhang, H. Li and G. Liu, Green Chem., 2014, 16, 3401-3427; (c) B. Karimi, F. Mansouri and H. M. Mirzaei, ChemCatChem, 2015, 7, 1736-1789; (d) A. Baeza, G. Guillena and D. J. Ramón, ChemCatChem, 2016, 8, 49-67.

29 B. Sreedhar, A. S. Kumar and D. Yada, Synlett, 2011, 10811084.

30 W. S. Lee, S. Byun, J. Kwon and B. M. Kim, Bull. Korean Chem. Soc., 2016, 37, 1992-1997.

31 L. Zhang, P. Li, H. Li and L. Wang, Catal. Sci. Technol., 2012, 2, 1859-1864.

32 K. Karami, N. Jamshidian, M. M. Nikazma, P. Hervés, A. R. Shahreza and A. Karami, Appl. Organomet. Chem., 2018, 32, e3978.

33 (a) M. Hosseini-Sarvari, Z. Razmi and M. M. Doroodmand, Appl. Catal., A, 2014, 475, 477-486; (b) T. Chatterjee, R. Dey and B. C. Ranu, J. Org. Chem., 2014, 79, 5875-5879.

34 M. Hosseini-Sarvari and Z. Razmi, Helv. Chim. Acta, 2015, 98, 805-818. 
35 M. Hosseini-Sarvari and Z. Bazyar, ChemistrySelect, 2018, 3, 1898-1907.

36 M. M. Amini, A. Mohammadkhani and A. Bazgir, ChemistrySelect, 2018, 3, 1439-1444.

37 V. Kandathil, R. B. Dateer, B. Sasidhar, S. A. Patil and S. A. Patil, Catal. Lett., 2018, 6, 1562-1578.

38 A. R. Hajipour and P. Abolfathi, Catal. Commun., 2018, 103, 92-95.

39 (a) M. Blosi, S. Ortelli, A. Costa, M. Dondi, A. Lolli, S. Andreoli, P. Benito and S. Albonetti, Materials, 2016, 9, 550-575; (b) G. Sharma, A. Kumar, S. Sharma, M. Naushad, R. P. Dwivedi, Z. A. ALOthman and G. T. Mola, J. King Saud Univ., Sci., 2017, DOI: 10.1016/j.jksus.2017.06.012.

40 R. Narayanan, Molecules, 2010, 15, 2124-2138.

41 R. K. Rai, D. Tyagi, K. Gupta and S. K. Singh, Catal. Sci. Technol., 2016, 6, 3341-3361.

42 L. D. Pachón, M. B. Thathagar, F. Hartl and G. Rothenberg, Phys. Chem. Chem. Phys., 2006, 8, 151-157.
43 A. Ohtaka, J. M. Sansano, C. Nájera, I. Miguel-García, Á. Berenguer-Murcia and D. Cazorla-Amorós, ChemCatChem, 2015, 7, 1841-1847.

44 Q. Xiao, S. Sarina, A. Bo, J. Jia, H. Liu, D. P. Arnold, Y. Huang, H. Wu and H. Zhu, ACS Catal., 2014, 4, 1725-1734.

45 T. Chatterjee, R. Dey and B. C. Ranu, New J. Chem., 2011, 35, 1103-1110.

46 A. Grirrane, H. Garcia and A. Corma, J. Catal., 2013, 302, 4957.

47 M. Planellas, Y. Moglie, F. Alonso, M. Yus, R. Pleixats and A. Shafir, Eur. J. Org. Chem., 2014, 3001-3008.

48 D. Gaikwad, K. Undale, D. Patil, D. Pore and A. Kamble, Res. Chem. Intermed., 2018, 44, 265-275.

49 R. Dey, K. Chattopadhyay and B. C. Ranu, J. Org. Chem., 2008, 73, 9461-9464.

50 D. Srimani, A. Bej and A. Sarkar, J. Org. Chem., 2010, 75, 4296-4299.

51 J. Song, X. Feng, Y. Yamamoto, A. I. Almansour, N. Arumugam, R. Suresh Kumar and M. Bao, Asian J. Org. Chem., 2017, 6, 177-183. 